\title{
Experimental investigation of the thermoelastic performance of an aerospace aluminium honeycomb composite panel
}

\author{
Olga A. Ganilova ${ }^{1 *}$, Matthew P. Cartmell ${ }^{1}$, and Andrew Kiley ${ }^{2}$ \\ ${ }^{1}$ Aerospace Centre of Excellence, Department of Mechanical \& Aerospace Engineering, \\ University of Strathclyde, Glasgow, G1 1XJ, Scotland, UK. \\ ${ }^{2}$ Airbus Defence \& Space Ltd., Gunnels Wood Road, Stevenage, Hertfordshire, SG1 \\ 2AS, UK
}

\begin{abstract}
Aluminium composite sandwich panels are widely used to enhance the design of structures subjected to dynamic mechanical loading in thermally harsh environments. Spacecraft structures fall into this category because typical environmental conditions include combined and variable mechanical and thermal loading. Usually mechanical loadings arise as a consequence of localised structural dynamics and the thermal loadings are attributable principally to the effects of solar irradiation and eclipse during the vehicle's orbit. Together these have the potential to influence satellite de-point in particular. Therefore, building a combined physics model which is representative of the thermal and mechanical loadings has emerged as an interesting and useful aim, which can be thought of as defining an important thermoelastic deformation problem in this application. The performance of such a structure loaded in this way could obviously be considered in the context of separate thermodynamic and mechanical interpretations. However, multiphysics modelling is currently in hand based on the premise that the pseudo-static thermal loadings and the mechanical loadings encountered in various operating environments are not necessarily decoupled processes, and this will be the subject of a separate publication. The analytical modelling fully represents both static and dynamic mechanical and thermal loading conditions.

It has become clear that predictive accuracy may be compromised by separation of the phenomena, at least without the introduction of a judicious correction factor. Therefore, in this paper an attempt has been made to identify experimentally the presence, and then to understand the attendant effects, of the coupling between the thermal and mechanical effects in an aluminium composite sandwich panel under test. The authors have performed a series of experiments on an aluminium honeycomb composite panel under three-point mechanical bending and controlled environmental temperature. The panel was subjected to a controllable, centrally located, very slowly increasing mechanical load in conjunction with thermal loading in the form of precisely controlled lowered and elevated environmental temperature. The tests were performed on a computer controlled Instron $8801100 \mathrm{kN}$ test machine for which the rate of change of applied mechanical load was automatically linked through feedback control to the rate of change of displacement. This ensured that the exact load-deflection profile can be obtained, even for materials with highly nonlinear characteristics.

Both forms of loading have been shown to influence the displacement of the panel in significant ways, thereby confirming the importance of a combined physics approach.

\section{Introduction}

The materials used on the exterior of spacecraft are subjected to many environmental threats that can degrade them quite quickly, including the vacuum of space itself, solar ultraviolet (UV) radiation, ionising charged particle radiation, plasma, surface charging and arcing, temperature extremes, thermal cycling, impacts from micrometeoroids and orbital debris (MMOD), and environment-induced contamination. In terms of material degradation in

*Corresponding author.E-mail: olga.ganilova@strath.ac.uk.
\end{abstract}


space, low-Earth orbit (LEO), defined as the region from 200 to $1000 \mathrm{~km}$ above the Earth's surface, is a particularly harsh environment because of the presence of atomic oxygen (AO) along with the other detrimental environmental components and effects [1]. The environmental threats of space to spacecraft components vary in their influence mainly due to the specific material properties of the component and its structural interconnections, its geometry, and the stresses that it undergoes during normal duty. All orbiting spacecraft move in and out of sunlight during their progress around Earth and the degree to which a material experiences thermal cycling temperature extremes depends on its thermo-optical properties (specifically solar absorptance and thermal emittance), its exposure to the sun, its view of Earth and other surfaces of the spacecraft, the duration of time in direct sunlight and shadow, its thermal mass, and the influence of equipment or components that produce heat [1]. As a rule, the cyclic temperature variation is from $-120{ }^{\circ} \mathrm{C}$ to $+120{ }^{\circ} \mathrm{C}$ but high solar absorptance with low infrared emittance can contribute to even greater temperature swings [1]. The ISS orbits Earth approximately once every 92 minutes and therefore experiences sixteen thermal cycles a day, and this can lead directly to cracking, peeling, spalling or the formation of pinholes in the coating, which then allows AO to attack the underlying material [1].

The main forms of environmental heating on orbit are sunlight, sunlight reflected from Earth, a planet, or the Moon, and infrared energy emitted directly from Earth. During launch or in exceptionally low orbits, there is also a free molecular heating effect caused by friction in the rarified upper atmosphere [2]. Therefore, the main conditions of LEO that may be highlighted are the severe temperature extremes and the thermal cycling experienced throughout the orbit, with an orbiting spacecraft typically completing from eleven to sixteen thermal cycles daily, all within a temperature range of approximately $-120{ }^{\circ} \mathrm{C}$ to $+120{ }^{\circ} \mathrm{C}$. The thermo-optical properties of the spacecraft itself can also play a part in the temperature that it reaches. For instance, a material with high solar absorptance and low thermal emittance will experience greater temperature swings.

In [3] an experiment was performed to investigate the thermal behaviour of a sandwich panel which was to be deployed as an integral part of a satellite in the space environment, by means of a ground thermal-vacuum test. It was highlighted that the heat sink, solar radiation, infrared radiation of the Earth, heat conduction, surface radiation and cavity radiation would all influence the temperature field, and the conclusion was that these combined effects would present a serious challenge for realistic thermal testing in the laboratory of the simulated space environment. The experiment was relatively sophisticated and satisfied the general requirements for the inclusion of three key conditions: ultra-high level of vacuum (lower than $10^{-5} \mathrm{~Pa}$ ), a heat sink (down to $-180^{\circ} \mathrm{C}$ ) achieved in this case by using black panels with a liquidnitrogen cooling system, and thermal loading achieved through infrared lamps. An interesting study carried out by [4] focused on the effect of thermal cycling in a simulated LEO environment on the microhardness of aluminium alloys, and subjected these alloys to cycles ranging from $-140{ }^{\circ} \mathrm{C}$ to $+110{ }^{\circ} \mathrm{C}$. This was in order to induce thermal fatigue and to study the resulting stress state and mechanical properties of the material. The testing resulted in cyclic plastic deformation which was found to lead to crack initiation, identified using a transmission electron microscope (TEM). A test totalling 400 thermal cycles was carried out on the samples and these showed an eventual decrease in hardness, and then from 300-400 cycles the hardness started to increase with every cycle. Although rapid temperature changes were implied, the exact value of the rate of change of temperature was never stated in the study. The mechanical load was applied at intervals to test the microhardness of the material and was not applied simultaneously with the change in temperature. The study concluded that the bulk of aerospace materials that undergo periodic heating and cooling are damaged to varying degrees, with thermal fatigue having a significant impact on the mechanical properties of the materials used. Although it is difficult to recreate truly the conditions of LEO on Earth, such work has been attempted in the past by [5]. The study focused on subjecting graphite-epoxy composites to the conditions of LEO. Not only did the materials undergo thermal cycling similar to that experienced in LEO, but the environment was also in a high vacuum state while the effect of 
ultraviolet radiation was applied during heating but not during cooling. A single thermal cycle was judged to be from $-70{ }^{\circ} \mathrm{C}$ to $+100{ }^{\circ} \mathrm{C}$ and back to $-70{ }^{\circ} \mathrm{C}$ again. This was with a rate of change of temperature of $3-5^{\circ} \mathrm{C}$ per minute and a dwell-time at the temperature extremes of 15 minutes, giving an average cycle time of 100 minutes, typical of a low Earth orbital period. The results examined were for composites subjected to this environment for 8, 16, 40 and 80 thermal cycles, in which the transverse flexural strength and transverse tensile strength showed the most severe reduction with thermal cycling, after 80 thermal cycles, with losses of $34 \%$ and $21 \%$ in each property respectively. It was considered that the matrix-dominated mechanical properties suffered the greatest loss, due to high vacuum and thermal cycling. Overall, the strength and stiffness of graphite epoxy composites was shown to decrease exponentially with increasing thermal cycles. Further work into the synergistic effects of high vacuum and thermal cycling was implemented by [6], this time on carbon fibre epoxy composites. The experiment took place in a high vacuum state of $133 * 10^{-5} \mathrm{~Pa}$, and a single thermal cycle was judged to be from $+120^{\circ} \mathrm{C}$ to $-175^{\circ} \mathrm{C}$ and back to $+120^{\circ} \mathrm{C}$, with a duration of approximately 43 minutes. The experiment was run for 500, 1000, 1500 and 2000 cycles. Panels were then subjected to mechanical tests at an ambient temperature of $23{ }^{\circ} \mathrm{C}$ to observe the mechanical properties of the samples. The results confirmed the onset of gradual damage with increasing thermal cycles. This was coupled with the degradation of the fibre-matrix interface due to a weakened fibre-matrix bond, which led to interfacial sliding.

Some industrial experiments [7] involving the thermal loading of aluminium composite panels, but not using temperatures as extreme as those experienced in LEO, measured thermoelastic deformation under thermal load with temperature steps from $-20{ }^{\circ} \mathrm{C}$ to $+40{ }^{\circ} \mathrm{C}$ and with static loads imposed on the panel between 0 and $78 \mathrm{~N}$ - in steps of $19.6 \mathrm{~N}$. The experiment was carried out in a climatic chamber with the measurements being corroborated by a finite element model. Measurements for the deflection and sample temperature of the structural model were taken at set temperatures using photogrammetry and infrared cameras to map a thermal cartographic image of the structural model, where temperatures were assumed as for black body conditions. Looking at the problem of a spacecraft panel undergoing cyclic loading from the perspective of modelling it is possible to find that the structure must combine the effects of thermal loading as well as mechanical disturbance. This is because from a physical point of view the deformation of a body is connected to a change of heat inside it, and therefore to a change of the temperature distribution in the body. So, a deformation of the body leads to temperature changes, and conversely. The internal energy of the body depends on both the temperature and the deformation and so, in the case of a practical body, such as a spacecraft panel, this necessarily undergoes processes that are intrinsically coupled, defined collectively as thermoelasticity [8].

However, thermoelasticity deals with a wide class of phenomena. It covers the general theory of heat transfer as well as the general theory of thermal stresses, and it describes the temperature distribution produced by deformation. Thermoelasticity also describes the phenomenon of thermoelastic dissipation. As mentioned above many modelling approaches tend to separate the mechanical and thermal effects, but thermoelastic processes are not generally reversible because although the elastic part may be reversed - the deformations may be recoverable through cooling - the thermal part may not be reversible due to the dissipation of energy during heat transfer [9].

Apart from that, thermal changes in the body cause mechanical deformation in the body, which in return affects these thermal changes, involving a two-way feedback. This means that the modelling techniques and representations really do have to couple the mechanical and thermal aspects of the problem to achieve results of adequate accuracy that describe the problem properly.

It should also be mentioned that in recent years, honeycomb panels have become more and more widely used within the aerospace industry [4, 10-12] due to their structural efficiency, and because they demonstrate a generally high strength to weight ratio. This type of design consists of two thin parallel face sheets - usually coated - attached to a core material that 
separates them. The core can be composed of different types of material, but the most frequently used one is a hexagonal honeycomb made from sheets of aluminium foil, as shown in Figure 1.

Figure 1. A honeycomb sandwich panel as typically used in the aerospace industry

Despite their many benefits sandwich panels do have a number of structural limitations. They are known to have poor resistance to impact loads, particularly when combined with thermal loading, due to the risk of debonding between the sandwich core and the outer faces under these conditions.

It has been found in the literature that honeycombs with thicker core are characterised by higher strength [10] and an increase in the core density leads to an increased stiffness of the sandwich structure [11]. It was also shown experimentally in [13] that a change in honeycomb cell size, as well as in the distance between the supports, has an impact on the collapse mode of the samples.

In [14] a thermal effect of the inserts in the honeycomb core was demonstrated. It was concluded that any electronic equipment (including batteries) that might be attached to the honeycomb would cause dissipation of possibly excessive heat through the inserts causing additional thermal loading within the panel.

Therefore, to the best of the authors' knowledge, there has not yet been an experimental investigation on the behaviour of an aluminium sandwich panel undergoing simultaneous thermal and dynamic mechanical loading to investigate coupling between the two of them and the response of the panel to harsh thermal environments of up to $+100^{\circ} \mathrm{C}$ and down to $-150^{\circ} \mathrm{C}$. Most authors consider the heat distribution within the material for mechanical testing performed after the thermal cycling has been completed. Thus, in this paper we consider, for the first time, the thermoelastic response of a typical aluminium honeycomb sandwich panel when tested for load defection characteristics within an environmentally controlled enclosure. It should be noted that this type of structural panel is routinely used within spacecraft structures.

\section{Experimental set-up}

In order to plan an appropriate experiment a literature review was undertaken in order to study the basic thermal properties of the space environment that would necessarily have to be emulated. It became evident that the International Space Station (ISS) environment would include exposure to extreme thermal cycling, ultra-vacuum, atomic oxygen, and high energy radiation [1]. As discussed previously when an orbiter such as the ISS moves in and out of sunlight during its orbit around Earth the degree to which the outer structural materials experience thermal cycling temperature extremes depends on their thermo-optical properties (solar absorptance and thermal emittance), exposure to the sun, their view of Earth and the other surfaces of the spacecraft, the duration of time spent in sunlight and shadow, the important thermal masses and the influences of nearby onboard equipment and components that produce heat [1]. As a rule, the cyclical temperature variation was taken to be $-120{ }^{\circ} \mathrm{C}$ to $+120{ }^{\circ} \mathrm{C}$, acknowledging that high solar absorptance with low infrared emittance will contribute to greater temperature swings.

Therefore, the test was designed to simulate the extreme thermal environments experienced by the sandwich panel of the spacecraft due to the solar radiation. Based on the information in the open literature summarised in Section 1, it was assumed that only solar radiation causes an extreme thermal impact on the spacecraft panel. Thus, the solar radiation was considered to vary, resulting in thermal loading from $-150^{\circ} \mathrm{C}$ up to $100{ }^{\circ} \mathrm{C}$.

The test sandwich panel of $300 \cdot 10^{-3} \times 100 \cdot 10^{-3} \times 15 \cdot 10^{-3} \mathrm{~m}$ was composed of two types of aluminium alloy. For the outer skins of thickness $0.38 \cdot 10^{-3} \mathrm{~m}$ an Al-2024 alloy was used, whilst an Al-5056 alloy foil was used to form the hexagonal honeycomb core. This core was of crosssectional thickness $14.24 \cdot 10^{-3} \mathrm{~m}$ and was made up from a foil of thickness $0.0254 \cdot 10^{-3} \mathrm{~m}$. The 
mechanical and thermal properties of these materials are summarised in Tables $1 \& 2$, noting that the structural coefficient of thermal expansion stated in Table 2 was extrapolated from the data made available for AL-5056.

Table 1. Mechanical properties of the sandwich panel

\begin{tabular}{clc}
\hline & Al-2024 & $\begin{array}{c}\text { Al-5056 } \\
3 / 16 \text { Honeycomb }\end{array}$ \\
\hline Density, $\rho\left(\mathrm{kg} / \mathrm{m}^{3}\right)$ & 2780 & 50 \\
Young's Modulus, E (Pa) & $73.1 \times 10^{9}$ & $669 \times 10^{6}$ \\
Shear Modulus, G (Pa) & $27.5 \times 10^{9}$ & $310 \times 10^{6}$ \\
Poisson's Ratio, $\nu$ & 0.33 & 0.3 \\
Foil thickness (m [in]) & & $0.0254 \times 10^{-3}[0.001]$ \\
\hline
\end{tabular}

Table 2. Thermal properties of the sandwich panel materials

\begin{tabular}{ccc}
\hline & Al-2024 & Al-5056 \\
\hline Coefficient of Thermal Expansion $\left(/{ }^{\circ} \mathrm{C}\right)$ & $2.47 \times 10^{-5}$ & $2.41 \times 10^{-5}$ \\
Coefficient of Thermal Expansion for & & $2.4 \times 10^{-6}$ \\
$3 / 16$ honeycomb $\left(/{ }^{\circ} \mathrm{C}\right)$ & 149 & 149 \\
Thermal Conductivity $@ 25^{\circ} \mathrm{C}(\mathrm{W} / \mathrm{mK})$ & 875 & 904 \\
Specific Heat $\left(\mathrm{J} / \mathrm{kg}^{\circ} \mathrm{C}\right)$ & 22 & 22 \\
Reference Temperature $\left({ }^{\circ} \mathrm{C}\right)$ & & \\
\hline
\end{tabular}

It was shown in [7] that typical models of the honeycomb panels do not take into account the fact that the temperature profiles within the thickness of the panel may vary, as in Figure 2.

Figure 2. Temperature profile of a honeycomb panel [7]

This was considered to be a very important point so it was decided to take thermal measurements not only on the top and bottom skins but from within the honeycomb layer as well, to record any disparity in the temperature within the honeycomb and the skins.

The experiment was performed in an environmental testing chamber fitted to a computer driven Instron $8801100 \mathrm{kN}$ tensile and compressive testing machine in the University of Strathclyde's Advanced Materials Research Lab (AMRL), shown in Figure 3.

Figure 3. Panel sample fitted within the Instron test machine's environmental chamber, also showing the liquid nitrogen dewar, and the nitrogen gas flow regulator system.

The environmental test chamber offers a temperature range of $-150{ }^{\circ} \mathrm{C}$ to $+350{ }^{\circ} \mathrm{C}$ and uses a liquid nitrogen cooling system. When the chamber is sealed there is no internal visible access, therefore the use of imaging equipment wasn't possible so strain gauges were used to register the displacement of the panel. High performance $\mathrm{C}$ series strain gauges from HBM UK were used, with an operating temperature range from -269 to $+250{ }^{\circ} \mathrm{C}$, and a nominal terminal resistance of $120 \mathrm{Ohms}$. 
To extract as much information as possible from the experiment a rosette configuration was used on the top and bottom faces, adjacent in each case to the centralised load point, with uniaxial gauges elsewhere, as shown in Figures 4 and 5.

Figure 4. Strain gauges rosette configuration shown on the upper face of the sample, and thermocouples $\mathrm{T}_{2}$, $\mathrm{T}_{3}$, and $\mathrm{T}_{4}$.

In order to record the temperature data on the panel sample within the chamber, as well as to validate the distribution of the heat flux within the panel, thermocouples of type $\mathrm{T}$ from RS Components Ltd were selected, with an operating range of $-200{ }^{\circ} \mathrm{C}$ to $+350{ }^{\circ} \mathrm{C}$. Six thermocouples were positioned on the top, bottom and middle layers of the panel to record the pattern of the temperature distribution in three dimensions, as shown in Figure 5.

Figure 5. Thermocouple distribution on the test panel (a) on the top surface of the sample and (b) on the top and bottom surfaces, as a schematic. Note that gauges T1 and T2 are located halfway down the edge thickness of the panel.

The experiment comprised a three point bending test, shown in Figure 6, with the sample honeycomb panel simply supported in the thermal chamber, undergoing an incremental mechanical loading profile with line contact established between a $6 \mathrm{~mm}$ diameter circular loading bar and the upper surface of the plate, orientated such that the loading line was across the width of the plate, and centrally located along the length. The loading and unloading procedure was automated using the built-in control options embedded in the software of the Instron testing machine. The loading starting from zero and gradually increasing up to $150 \mathrm{~N}$, and then back to zero, and this was repeated at specific temperatures over the full range of environmental temperatures required, as follows: $-150{ }^{\circ} \mathrm{C},-100{ }^{\circ} \mathrm{C},-60{ }^{\circ} \mathrm{C},-40{ }^{\circ} \mathrm{C},-20{ }^{\circ} \mathrm{C}, 20$ ${ }^{\circ} \mathrm{C}$ (ambient), $40{ }^{\circ} \mathrm{C}, 60{ }^{\circ} \mathrm{C}, 80^{\circ} \mathrm{C}$, and $100{ }^{\circ} \mathrm{C}$. It should be re-confirmed here that the process of cyclical loading and unloading, in the form of a dynamic mechanical load imposed over a range of different thermal environments has not been reported in the literature to date, to the authors' knowledge.

Figure 6. Three point bending test arrangement, looking end-on at the circular loading bar orientated across the width of the plate.

The overall aim of the experiment, and fundamental novelty of this work, has been to evaluate the nature and significance of the coupling between the mechanical and the thermal effects within an aluminium composite plate. In order to accomplish this successfully, given prior expectations from the literature, and insights gained from the authors' own modelling work that has been carried out as a parallel study, the following research hypotheses were formulated, as a general basis for observation and interpretation:

H1. Due to the different structural properties of the top, bottom, and middle plies of the sandwich panel, there may be a different distribution of temperature in the middle ply from that in the top and bottom layers. 
H2. Within the environmental chamber the environmental temperature is stabilised, but there may still be a significant disparity between the temperature recorded on the top and bottom skins.

H3. The environmental temperature may have a significant quantitative effect on the bending performance as well as a generally qualitative effect on the deformation of the panel, and this may be due to possible thermoelastic coupling between the thermal and mechanical loading effects.

H4. The qualitative deformation characteristics of the panel at extreme environment temperatures may differ significantly from those observed at environmental temperatures that are closer to moderate ambient temperatures.

In order to address these research questions systematically data was logged continuously for the applied load and the corresponding deflection at the load point, at the stabilised environmental temperature points, as well as local temperature data from the thermocouples located on the top and bottom skins and inside the honeycomb surface on the sides of the panel. This data set was then composed into suitable graphs for subsequent analysis. It should be noted that each set of deflection data was subject to a nonzero offset of magnitude 52.2707 $\mathrm{mm}$, (stated here to four decimal places to maintain the setup accuracy for the Instron 8801 machine, running under Bluehill ${ }^{\mathrm{TM}}$ control software) although the effects to be described are all based on relative displacements, so this offset only needs to be subtracted if absolute displacements are also required.

The remaining sections of the paper present the analysis and the findings that were deduced from this, leading to conclusions formulated in the context of the defining research questions.

\section{Results analysis and discussion}

\subsection{The effect of retention or loss of heat due to dynamic mechanical loading in extreme thermal environments, and the implications of this for modelling}

The full data set was initially considered from all the thermocouples $\left(\mathrm{T}_{1}-\mathrm{T}_{6}\right)$ and with respect to the mechanical loading. This first investigation of the data was undertaken in order to start to understand the effect of any possible cooperation between the mechanical loading and the thermal conditions of the environment, and also to ascertain the nature of the temperature distribution along the panel in different areas of the panel. Thus, the data was represented graphically as the temperature recorded by each thermocouple within the environmental temperatures $\left(T_{\text {env }}\right)$ of $-150{ }^{\circ} \mathrm{C},-100{ }^{\circ} \mathrm{C},-60{ }^{\circ} \mathrm{C},-40{ }^{\circ} \mathrm{C},-20^{\circ} \mathrm{C}, 20^{\circ} \mathrm{C}, 40{ }^{\circ} \mathrm{C}, 60$ ${ }^{\circ} \mathrm{C}, 80^{\circ} \mathrm{C}, 100{ }^{\circ} \mathrm{C}$ against the mechanical load from $0 \mathrm{~N}$ up to $150 \mathrm{~N}$.

Due to the constraints of space we present results from the 6 thermocouples only for two environmental temperatures of $-20^{\circ} \mathrm{C}$ and $-150{ }^{\circ} \mathrm{C}$, shown in Figures 7 and 8, together with summative findings from all data for all the environmental conditions considered. Graphical data for other environmental conditions are openly available from [15].

Figure 7. Temperature distribution from thermocouples $\mathrm{T}_{1}-\mathrm{T}_{6}$ as a function of loading $[0 \mathrm{~N}, 150 \mathrm{~N}]$ at the environmental temperature of $T_{\mathrm{env}}=-20{ }^{\circ} \mathrm{C}$. 
As a results of analysis of data obtained it can be seen that the same qualitative form of hysteresis is evident in the temperature readings from all the thermocouples $T_{1}-T_{6}$ for a specified environmental temperature $T_{\text {env }}$. An initial but very important conclusion from this is that all the thermocouples performed consistently and responded in the same manner to the local conditions in the material of the panel. It was also found that the hysteresis is represented by an open loop at the following environmental temperatures: $-20{ }^{\circ} \mathrm{C},-40{ }^{\circ} \mathrm{C}$, ambient, and + $40{ }^{\circ} \mathrm{C}$, see Figure 7 for the specific case of $T_{\mathrm{env}}=-20^{\circ} \mathrm{C}$. It is also seen that when operating closer to the ambient temperature, and if the panel then undergoes a cycle of loading and unloading, shown counter-clockwise on the Figure, then after unloading it does not return to its initial thermal state. Instead it retains some heat after unloading, resulting in a gain of 1-2 ${ }^{\circ} \mathrm{C}$ over the initial state, which is indicative of an irreversible process, as mentioned in [9].

The hysteresis is represented by a closed loop at the following environmental temperatures: $-150{ }^{\circ} \mathrm{C},-100{ }^{\circ} \mathrm{C},+60{ }^{\circ} \mathrm{C},+80^{\circ} \mathrm{C},+100{ }^{\circ} \mathrm{C}$, and refer to Figure 8 for the specific case of $T_{\text {env }}$ $=-150^{\circ} \mathrm{C}$. This means that the panel appears not to retain residual heat when operating at the more extreme levels of environmental temperature, irrespective of whether or not this is positive or negative, and so after unloading at those temperatures it returns, reversibly, to the thermal condition from which it started. This is a novel finding detected only because of the cyclical dynamic loading and unloading regime that was specifically undertaken at extreme temperatures.

It must be mentioned that there is a distinctly unstructured response within the loop at the specific case of $T_{\text {env }}=-60^{\circ} \mathrm{C}$, noting that this phenomenon occurred only at this particular environmental temperature and is probably an artefact of the specific material we have been considering. It is also evident that this unstructured behaviour occurs as a transition from the open loop hysteretic behaviour, which is found closer to the ambient environmental temperature, to the closed loop response which occurred at the more extreme environmental temperatures. The fact that we do not see a clear hysteretic loop for the loading process at this environmental temperature means we do not see a clear temperature difference for the loading and unloading processes. This means that the thermal response of the panel changes during loading and unloading, and so there might be a retention of heat within the panel, but we cannot predict from this data how much hotter the sample would be during the unloading process. Therefore, we cannot predict in this specific case the extent of the thermo-mechanical coupling, i.e. how the deformation that occurred resulted in a change of the thermal properties of the panel, and some further research around this phenomenon should be undertaken in the near future.

At the environmental temperature of $-100{ }^{\circ} \mathrm{C}$ the behaviour is characterised by a bow-like double loop which becomes a more clearly defined single loop when the environment becomes colder still at $-150^{\circ} \mathrm{C}$. It seems obvious that the environmental temperatures of $-60{ }^{\circ} \mathrm{C}$ and -100 ${ }^{\circ} \mathrm{C}$ are defining points at which there is a transition from an open hysteretic loop to one that is closed, and from an irreversible thermodynamic process to one that is reversible.

At the maximum load of $150 \mathrm{~N}$ it can be seen from Figure 8 that the loop ends at a single valued temperature for all the six thermocouples, and it was also noted that this is independent of the environmental temperature. This confirms the correctness of readings taken across the profile of thermocouples, and that the unloading phase starts from the point at which the maximum loading was reached.

Therefore the experimental results offer strong evidence of progress from an open hysteresis loop (at $-40{ }^{\circ} \mathrm{C},-20{ }^{\circ} \mathrm{C}$, and ambient temperature) towards a closed loop, and this progresses either in the positive or negative temperature directions starting from the ambient 
environmental temperature, up to the extreme values of $-150{ }^{\circ} \mathrm{C}$ and $+100{ }^{\circ} \mathrm{C}$. There is evidence that the hysteresis loop is structurally closed at the extreme environmental temperatures (very hot $\left[+100^{\circ} \mathrm{C}\right]$ and very cold $\left[-150^{\circ} \mathrm{C}\right]$ ), showing thermodynamic reversibility, and clearly open, and therefore thermodynamically irreversible, when the environmental temperature gets closer to $0{ }^{\circ} \mathrm{C}$. This means we can conclude that the loading of the panel in the extreme temperature environment does not cause an accumulation of any residual heat after unloading. However, during the processes of loading and unloading there is evidence of thermo-mechanical coupling, which results in the presence of extra heat internally compared with the heat available from the environment. However, at an environmental temperature close to the ambient temperature (noticed specifically at $-40{ }^{\circ} \mathrm{C},-20^{\circ} \mathrm{C}$, and at ambient itself) the open hysteretic loop confirms an accumulation of residual heat within the panel which is still present to a large extent even at the point of complete unloading of the deformed sample. This means that a correction factor has to be introduced for the thermal initial condition of a panel when it is close to ambient environmental temperature and when it has undergone a mechanical deformation, even if the loading has been completely removed, due to the tendency to irreversible thermodynamics at those environmental temperatures. Further research into the identification of this correction factor should be undertaken in the near future, as a priority.

It also has to be emphasised that the width of the hysteretic loop demonstrates the difference in the temperature of the sample at the position of loading and unloading, thus the extent of the heat that accumulates within the sample is due to the deformation, apart from that portion of heat that comes from the environment during the process of loading-unloading.

Table 3. Peak-to-peak (p-t-p) temperature range denoted by the width of the hysteresis loop

\begin{tabular}{|l|l|l|l|l|l|l|l|l|l|l|}
\hline$T_{\text {env }}$ & $-20^{\circ} \mathrm{C}$ & $-40^{\circ} \mathrm{C}$ & $-60^{\circ} \mathrm{C}$ & $-100^{\circ} \mathrm{C}$ & $-150^{\circ} \mathrm{C}$ & amb & $+40^{\circ} \mathrm{C}$ & $+60{ }^{\circ} \mathrm{C}$ & $+80^{\circ} \mathrm{C}$ & $+100{ }^{\circ} \mathrm{C}$ \\
\hline p-t-p & $2-3{ }^{\circ} \mathrm{C}$ & $2-3{ }^{\circ} \mathrm{C}$ & $1{ }^{\circ} \mathrm{C}$ & $2-3{ }^{\circ} \mathrm{C}$ & $2-3{ }^{\circ} \mathrm{C}$ & $1{ }^{\circ} \mathrm{C}$ & $1-2^{\circ} \mathrm{C}$ & $1{ }^{\circ} \mathrm{C}$ & $1{ }^{\circ} \mathrm{C}$ & $0.5^{\circ} \mathrm{C}$ \\
\hline
\end{tabular}

From Table 3 it is evident that the width of the temperature loop is the highest at an environmental temperature below $0{ }^{\circ} \mathrm{C}$. This means that the loading and unloading process of a panel placed in an environment at a temperature below $0{ }^{\circ} \mathrm{C}$ will be accompanied by a temperature swing of up to $3{ }^{\circ} \mathrm{C}$ due to the thermo-mechanical coupling. Therefore, the thermal properties for such a panel cannot be assumed to be governed just by the temperature of the environment if a panel of this sort undergoes a form of dynamic mechanical loading, but would need to have a correction factor applied to cater for the thermo-mechanical coupling, thus guaranteeing a higher level of accuracy of load-deflection prediction.

\subsection{Effect of the dynamic loading and extreme environmental temperature on the} temperature distribution along the surfaces and through the thickness of the panel

In order to analyse the temperature distribution at various locations of the panel it was decided to investigate how it differs from the temperature of the environment. Specific differences between the environmental temperature and the temperature feedback data from the individual thermocouples were evaluated. The intention was to see whether certain areas of the panel would heat up faster in response to the environmental temperature. This difference was considered graphically with respect to the mechanical loading of up to $150 \mathrm{~N}$ and then unloading from there back to $0 \mathrm{~N}$, for thermal environmental temperatures $\left(T_{\text {env }}\right)$ of $-150{ }^{\circ} \mathrm{C}$, $100{ }^{\circ} \mathrm{C},-60{ }^{\circ} \mathrm{C},-40{ }^{\circ} \mathrm{C},-20{ }^{\circ} \mathrm{C}, 20^{\circ} \mathrm{C}, 40{ }^{\circ} \mathrm{C}, 60^{\circ} \mathrm{C}, 80{ }^{\circ} \mathrm{C}$, and $100^{\circ} \mathrm{C}$.

In Figure 9 the results for $T_{e n v}-T_{i}$ are presented for all 6 thermocouples, taken for the environmental temperature of $-20{ }^{\circ} \mathrm{C}$ as an example, and this was calculated together with 
summative findings from all the data for all the environmental conditions mentioned. Graphical data for other environmental conditions are openly available from [15].

Figure 9. Distribution of the difference in temperature between the environmental temperature and the temperature recorded from the thermocouples $\left(T_{\text {env }}-T_{\mathrm{i}}\right)$ versus mechanical loading.

Referring again to Figure 5 we recall that thermocouples $T_{3}, T_{4}$ are placed on the top skin surface, $T_{5}$ and $T_{6}$ are placed on the lower surface of the bottom skin, and $T_{1}$ and $T_{2}$ are fitted on both sides, directly onto the honeycomb material. Now from Figure 9 it is evident that when the environmental temperature is negative all the thermocouple data demonstrates the same hysteretic loop behaviour. From this we can conclude that the cooling of the sample at all six locations occurs in the same manner, at the same rate, and with the same level of thermomechanical effect during the loading and unloading processes. Conversely when the environmental temperature is positive the thermocouple data shows a difference in the feedback from all the thermocouples, especially when the environmental temperature is between $+20^{\circ} \mathrm{C}$ and $+80{ }^{\circ} \mathrm{C}$. This confirms that the sample plate's heating-up process, during loading and unloading, can be faster at certain locations, especially when the environmental temperature is closer to ambient. Some distortion in the feedback from $\mathrm{T}_{4}$ and $\mathrm{T}_{6}$ is also evident, possibly because the strain gauges were attached to the skins very close to $T_{4}$ and $T_{6}$ which possibly resulted in a slight increase in the width of the hysteretic loop. When the environmental temperature is going up to extreme, between $+80{ }^{\circ} \mathrm{C}$ and $+100{ }^{\circ} \mathrm{C}$ all the thermocouples show results that demonstrate a generally flatter behaviour in the temperature loop output, with a peak-to-peak of around $0.5^{\circ} \mathrm{C}$. This means that the difference between the environmental temperature and the thermocouple readings is smaller, implying that the temperature of the panel is closer to the environmental temperature, and has minimal thermal distortion due to the imposed mechanical loading and thus characterises a weaker thermomechanical coupling.

\subsection{Effect of extreme environmental temperature on the panel deflection response under the imposed dynamic mechanical loading}

This investigation shows how the extreme environmental temperature affects the panel deformation in response to gradual mechanical loading ramping up to $150 \mathrm{~N}$ and back down to $0 \mathrm{~N}$. Data has been considered for the panel deflection versus loading over the range of environmental temperatures, as follows, $-150{ }^{\circ} \mathrm{C},-100{ }^{\circ} \mathrm{C},-60{ }^{\circ} \mathrm{C},-40{ }^{\circ} \mathrm{C},-20{ }^{\circ} \mathrm{C}, 20{ }^{\circ} \mathrm{C}, 40{ }^{\circ} \mathrm{C}$, $60{ }^{\circ} \mathrm{C}, 80{ }^{\circ} \mathrm{C}$, and $100{ }^{\circ} \mathrm{C}$.

In this part of the study results are presented for an environmental temperature of $-20{ }^{\circ} \mathrm{C}$ and also for the ambient temperature, as examples given in Figure 10, together with summative findings made available from the data for all the environmental temperatures under consideration. Graphical data for other environmental conditions are openly available from [15].

Figure 10. Deflection versus mechanical loading for two different thermal environments.

It can be seen in figure 10 that the load - deflection characteristics are consistent for both positive and negative environmental temperatures, meaning that the progressive changes in the panel deformation, this being the deflection at the load line, in response to the external loading 
on the panel has the same general trend for both hot and cool environmental conditions. There is no hysteretic behaviour in the load-deflection curve at the ambient temperature, but this characteristic then progresses into a clearer open hysteretic loop form as the environment gets colder or hotter, and it can be noted that in the case of the colder environments the width (i.e. the peak-to-peak) of the loop is wider. The peak-to-peak of the hysteretic loading and unloading loop is generally bigger for negative environmental temperatures, at around $0.1 \mathrm{~mm}$, than for the positive cases, but does build up again to approximately $0.1 \mathrm{~mm}$ at an environmental temperature of $+100^{\circ} \mathrm{C}$. The fact that there is no hysteresis effect apparent at the ambient temperature environment means that the loading and unloading progression there is characterised by the same values of deflection. This is in line with findings from [3] where either an additional deflection took place, or a shift in vibration frequency [16] was evident, in response to the thermal changes, especially as the temperature was increased up to extreme values. This means that the deflection values for panels which have undergone some deformation do not come back to the initial values after removal of loading for hotter and especially for colder environments, and are characterised by some residual stress, and characterised thermodynamically by irreversibility. The extent of this residual stress is dependent on the environmental temperature to which the panel is exposed. Thus, another correction factor has to be introduced to account for the effect of the environmental temperature on the magnitude of the deformation of the panel. This further confirms the presence of thermomechanical coupling, especially for the colder environments. Therefore, in order to produce an accurate prediction of the deformation progression and regression during the loading and unloading processes, the environmental temperature should be the basis for introducing another correction factor for the deflection responses.

\subsection{Effect of deflection on the temperature distribution along the surface and through the thickness of the panel in extreme environmental temperatures}

This penultimate analysis was undertaken to find out if the environmental temperature affects not only the deflection of the panel but also if the deflection affects the temperature distribution along the panel. This potentially provides a novel perspective into the general problem, since the combination of dynamic mechanic loading within extreme thermal environments has not been investigated before, to the authors' knowledge. To investigate this it was decided to consider how the temperature distribution in certain locations of the panel is affected by the induced deflection. Thus, the temperature feedback from thermocouples $\mathrm{T}_{1}-\mathrm{T}_{6}$ at different locations of the panel has been considered against deflection within the discrete fixed thermal environmental temperatures of $-150{ }^{\circ} \mathrm{C},-100^{\circ} \mathrm{C},-60{ }^{\circ} \mathrm{C},-40{ }^{\circ} \mathrm{C},-20{ }^{\circ} \mathrm{C}, 20{ }^{\circ} \mathrm{C}, 40{ }^{\circ} \mathrm{C}, 60{ }^{\circ} \mathrm{C}$, $80{ }^{\circ} \mathrm{C}$, and $100^{\circ} \mathrm{C}$.

Results are shown in Figure 11 for all 6 thermocouples at the environmental temperature of $-20{ }^{\circ} \mathrm{C}$ as an example, again together with the summative findings made available from the data taken for all the environmental conditions. Graphical data for other environmental conditions are openly available from [15].

Figure 11. Fluctuation of the temperature feedback data from the thermocouples $\mathrm{T}_{1}-\mathrm{T}_{6}$ with respect to the increasing deflection due to a loading ramped up to $150 \mathrm{~N}$ and then back to $0 \mathrm{~N}$, subjected to an environmental temperature of $-20^{\circ} \mathrm{C}$. 
As it can be noted from Figure 11, the readings from all the thermocouples show the same trend with respect to the deflection within a certain environmental temperature $T_{\text {env }}$, except for the case of the ambient temperature for which $\mathrm{T}_{5}$ shows a flatter hysteretic loop, and $\mathrm{T}_{6}$ shows a wider loop for this thermocouple. This means that the deflection response from the surface of the panel appears to be the same, independent of the location of the thermocouples, except for the case of ambient environmental temperature. Although the thermal feedback is consistent for all thermocouples within a certain environment, there is an evidence that the temperature of the environment $T_{\text {env }}$ is significant and changes the trend of the deflection-temperature behaviour of the panel. For the environment characterised by a negative temperature the peakto-peak temperature variation, with respect to the deflection is around $2.5^{\circ} \mathrm{C}$, and for the positive temperature environment the peak-to-peak decreases from $1.2^{\circ} \mathrm{C}$ down to $0.5^{\circ} \mathrm{C}$ at the hottest environment of $+100{ }^{\circ} \mathrm{C}$. There is also a dramatic difference in the way the thermal changes occur in the panel due to the deformation for different extreme environmental temperatures. This means the connection between the thermal properties of the panel and its deformation, and how they affect each other as the deformation progresses, and essentially what defines the thermo-mechanical coupling, is affected by the environmental temperature within which the panel is immersed. There is hysteresis to be found in the thermal response to the deformation, and this gets more significant in the colder environments which was observed earlier on as well. The thermal properties of the panel demonstrate this through a swing in the temperature of the panel of $2.5^{\circ} \mathrm{C}$ during the unloading process. The patterns of open and closed hysteresis loops are the same as for the loading-temperature feedback from the thermocouples in section 3.1, closing for the environmental temperatures above $+60{ }^{\circ} \mathrm{C}$ and below $-100{ }^{\circ} \mathrm{C}$. As in section 3.1 the hysteresis loop is closed to a single value at the maximum value of deflection. This confirms that there is a direct connection between loading and deflection, and the readings are consistent with the data presented for loading versus temperature of the panel. This is a good control point for verifying that the results are consistent for deflection and loading.

It is interesting to note that when going into the extremely cold or hot environments the pattern of temperature feedback from the panel, with respect to the deflection, bifurcates as shown in Figure 12. This demonstrates how significant the thermal changes in the environment can change the qualitative aspects of the coupling between the thermal properties and the mechanical deformation of the panel.

Figure 12. Fluctuation of the temperature feedback from the thermocouple $\mathrm{T}_{3}$ with respect to the increasing deflection due to loading up to $150 \mathrm{~N}$ and back to $0 \mathrm{~N}$, within the environments of (a) $-150{ }^{\circ} \mathrm{C}$ and (b) $100{ }^{\circ} \mathrm{C}$.

\subsection{Effect of simultaneous mechanical loading and extreme environmental temperatures on the heating-up and cooling-down processes within the panel}

Thermocouple data at fixed loading and unloading points can be used to understand in a clearer way how the temperature is distributed along the whole panel, and how thermal conditions of certain areas of the panel are affected by the mechanical loading as well as the extreme environmental temperature. For this part of the study the following specific loading values were taken, noting that a small amount of approximation was inevitable in extracting this particular data: $0 \mathrm{~N}, 50 \mathrm{~N}, 100 \mathrm{~N}, 150 \mathrm{~N}, 100 \mathrm{~N}$ [unloading], $50 \mathrm{~N}$ [unloading] within the environmental temperatures of $-150{ }^{\circ} \mathrm{C},-100{ }^{\circ} \mathrm{C},-60{ }^{\circ} \mathrm{C},-40{ }^{\circ} \mathrm{C},-20{ }^{\circ} \mathrm{C}, 20{ }^{\circ} \mathrm{C}, 40{ }^{\circ} \mathrm{C}, 60{ }^{\circ} \mathrm{C}$, $80{ }^{\circ} \mathrm{C}$, and $100{ }^{\circ} \mathrm{C}$. 
Results are shown in Figure 13 for the environmental temperatures of $-20{ }^{\circ} \mathrm{C}$ and $-150{ }^{\circ} \mathrm{C}$ as examples, noting that summative findings are openly available for all the environmental conditions mentioned from [15].

Figure 13. Temperature feedback from the thermocouples $\mathrm{T}_{1}-\mathrm{T}_{6}$ with respect to the loading ramping up to $150 \mathrm{~N}$ and back to $0 \mathrm{~N}$ within the environments of (a) $-20^{\circ} \mathrm{C}$ and (b) $-150^{\circ} \mathrm{C}$.

From Figure 13(b) it can be noted that thermocouples $T_{3}$ and $T_{5}$ record the highest temperature readings for most cases, and for a variety of environmental temperatures, and $\mathrm{T}_{4}$ and $\mathrm{T}_{6}$ sense the lowest temperature readings. The exception to this seems to be at the environmental temperatures closest to $0{ }^{\circ} \mathrm{C}$, i.e. $+20{ }^{\circ} \mathrm{C}$ and $-20{ }^{\circ} \mathrm{C}$, for which $\mathrm{T}_{1}$ and $\mathrm{T}_{2}$ detect the lowest temperature and at $+40^{\circ} \mathrm{C}$ when the highest temperature is demonstrated by $\mathrm{T}_{4}$ and the lowest by $\mathrm{T}_{5}$. From this data it is evident that in the environment where the temperature is close to the ambient the skins do heat up faster than the honeycomb core, however this trend disappears as the temperature moves to higher or lower extremes. As mentioned in section 3.2, the proximity of the strain gauges to the $T_{4}$ and $T_{6}$ thermocouples seems to influence the response, and, as a result, those thermocouples sensed a lower panel skin temperature than thermocouples $\mathrm{T}_{3}$ and $\mathrm{T}_{5}$. It is possible to speculate from this that any reasonably significant geometrical imperfections, or extrusions, probably have to be accounted for when attempting to assimilate the thermal properties of the panel into the thermoelastic performance with full accuracy.

\section{Conclusions}

As a result of the analyses subsequently conducted on the data generated by this experiment it has been found that there is a strong evidence of the thermo-mechanical coupling effect when the panel is immersed in an environment with extreme temperature, and is loaded mechanically.

There are experimental precedents for the coupling of mechanical and thermal loading in certain structures, notably in NiTi-PU composites [17], and also for complex internal dissipation effects within aluminium structural elements constructed into the form of braced shear panels [17]. In addition, it is shown in [19] that hysteretic responses to mechanical loading are typically encountered in many different types of composite, in addition to plasticity effects due to isotropic strain hardening where post-yield hardening is observed. It is also pointed out in the conclusions to [19] that a mathematical model that properly represents the inherent hysteresis in a composite can potentially be used as a basis for thermo-mechanical simulations. It is interesting to note that the experimental results obtained in [17] explicitly confirm that for a given composition of the NiTi-PU composite the bending modulus and the area of the load-deflection hysteresis loops both decrease with increasing test temperature over the investigated range of $0-50{ }^{\circ} \mathrm{C}$. It is the case that the phenomenology discussed in [17-19] is specific to those particular material compositions, and different in each study, and therefore not exactly the same as reported here. But it is important to note that there are parallels in terms of the stated thermo-mechanical dependencies with some of the key observations made in this paper.

On the basis of the experimental work reported in this paper, there is evidence that thermal loading caused by the extreme environment affects the deflection value and the level of residual stresses, and conversely the mechanical loading affects the heat accumulation and distribution within the panel. The following points may be made to elaborate a little further on this general finding. 
- The extreme temperature environment does not cause an accumulation of any residual heat after unloading. However, during the processes of loading and unloading there is evidence of thermo-mechanical coupling which results in the presence of extra heat internally within the structure comparing to the heat available from the environment, and this can result in a temperature swing of up to $3{ }^{\circ} \mathrm{C}$. If the environmental temperature is close to the ambient temperature (specifically noted for the cases at $-40{ }^{\circ} \mathrm{C},-20^{\circ} \mathrm{C}$, and ambient) then there is an accumulation of residual heat within the panel which is still present to a large extent even at the point of complete unloading of the deformed sample, indicating thermodynamic irreversibility for an environmental temperature close to the nominal ambient.

- It was found that the environmental temperature effect is significant and that it changes the trend of the deflection - temperature behaviour of the panel. The deflection of the panel affects the distribution of the heat within the panel resulting in a localised temperature swing in the material of around $2.5{ }^{\circ} \mathrm{C}$ if deformed in a cool environment and up to $1.2{ }^{\circ} \mathrm{C}$ in warmer environments;

- There was no evidence of residual stress accumulation only in the case of the panel operating in the ambient temperature environment. For negative environmental temperatures and the higher positive temperatures the deflection values for a panel which has already undergone some deformation did not come back to the initial values after the removal of the loading, and were characterised by the presence of some residual stress, and thermodynamic irreversibility. The extent of this residual stress is dependent on the environmental temperature within which the panel is immersed. For the sample considered here the deflection during unloading in a very cold environment could reach up $0.1 \mathrm{~mm}$ lower than the corresponding value during loading. This confirms the damaging effect of thermal loading on mechanical properties described in [4-6].

- Although there was no significant thermal swing initiated by deflection within the panel geometry at a certain fixed environmental temperature, there is a dramatic difference in the way the thermal changes occur in the panel due to the deformation for different hot or cold environments. This means that the connection between the thermal properties of the panel and deformation, and how they affect each other as the deformation progresses - constituting the thermo-mechanical coupling within the panel, is defined by the temperature of the environment in which the panel is immersed. There is hysteresis to be found in the thermal response to the deformation, which gets more significant for the colder environments, and the thermal properties of the panel demonstrate this through a swing in the temperature of the panel of $2.5^{\circ} \mathrm{C}$ during the unloading process.

Therefore, in order to produce an accurate prediction of the deformation progression and regression during the loading and unloading processes, as well as the heat distribution along the panel geometry, it is recommended to introduce corresponding correction factors to account for:

- the effect of the environmental temperature on the magnitudes of the deformation of the panel;

- the initial thermal conditions of a panel which has undergone a mechanical deformation, even if the loading has been completely removed. The thermal properties for such a panel cannot necessarily be assumed to be fully controlled by the value of the environmental temperature if the panel also undergoes mechanical loading.

This study has shown that the panel tends to cool down in a relatively uniform way in all three dimensions. However, the heating up process is not uniform and there is some localised heating 
resulting in certain hot-spot areas accumulating more heat than others. This is the case if the panel is in an environmental temperature between ambient and $+80^{\circ} \mathrm{C}$. In the more extreme thermal environment the sample heats up more evenly and reflects the temperature of the environment linearly, even while being mechanically loaded. It can be noted that in [13] where an attached battery resulted in higher heat, there was also evidence of increased heat around the attached strain gauges, noting that these are passive devices that are conducting small currents due to their connection to the conditioning bridge electronics.

From the data obtained during this experimental work it is evident that in the environment with the temperature close to the ambient the skins do heat up faster than the honeycomb core, however this trend disappears as the environmental temperature moves to higher or lower extremes.

An interesting observation is that when going into the more extreme hot or cold environments the pattern of temperature feedback from the panel, with respect to the deflection, bifurcates, as shown in Figure 12, demonstrating how significant the thermal changes of the environment can be for the pattern of the coupling between the thermal properties and the mechanical deformation of the panel.

\section{Funding Acknowledgements}

The first two authors would like to acknowledge the financial support made available by Airbus Defence \& Space Ltd and also the award of funding from the Strathclyde Centre for Doctoral Training. The authors would also like to thank Airbus Defence \& Space Ltd for confidential access to data, noting that no disclosure of any such data whatsoever has been made within this paper.

\section{Data Availability}

All data underpinning this publication are openly available from the University of Strathclyde at: https://doi.org/10.15129/28a67ac3-0daf-4c8d-81c7-3af6a847c211

\section{References}

[1] Finckenor MM, De Groh KK (2016) A Researcher's guide to space environmental effects. International Space Station. NASA. NP-2015-03-015-JSC. Available at: https://www.nasa.gov/connect/ebooks/researchers_guide_space_environment_detail.html (accessed 13 August 2020)

[2] Gilmore DG. Spacecraft thermal control handbook. Fundamentals Technologies. The Aerospace Corporation, 2002.

[3] Bai JB, Shenoi RA, Xiong JJ. Thermal analysis of thin-walled deployable composite boom in simulated space environment. Composite Structures 2017;173:210-218.

[4] Lv P, Zhang Z, Ji L, et al. Microstructure Evolution of 2024 and 7A09 Aluminium Alloys Subjected to Thermal Cycling in Simulated LEO Space Environment. Materials Research Innovations 2013;18 (3):169-175. 
[5] Shin K, Kim C, Hong C, et al. Prediction of Failure Thermal Cycles in Graphite/Epoxy Composite Materials under Simulated Low Earth Orbit Environments. Composites Part B: Engineering 2000;31(3):223-235.

[6] Park S, Choi H, Choi W, et al. Effect of Vacuum Thermal Cyclic Exposures on Unidirectional Carbon Fiber/Epoxy Composites for Low Earth Orbit Space Applications. Composites Part B: Engineering 2012;43(2):726-738.

[7] Airbus Defence and Space. Confidential communication, 2019.

[8] Nowacki W. Thermoelasticity. Pergamon press, 1986.

[9] Brischetto S, Carrera E. Coupled thermo-mechanical analysis of one-layered and multilayered plates. Composite Structures 2010;92:1793-1812.

[10] Paik J, Thayamballi A, Kim G. The Strength Characteristics of Aluminium Honeycomb Sandwich Panels. Thin-Walled Structures 1999;35(3):205-231.

[11] Abbadi A, Koutsawa Y, Carmasol A, et al. Experimental and Numerical Characterization of Honeycomb Sandwich Composite Panels. Simulation Modelling Practice and Theory 2009;17(10):1533-1547.

[12] Belingardi G, Martella P, Peroni L. Fatigue Analysis of Honeycomb-Composite Sandwich Beams. Composites Part A: Applied Science and Manufacturing 2006;38(4):1183-1191.

[13] Crupi V, Epasto G, Guglielmino E. Collapse Modes in Aluminium Honeycomb Sandwich Panels under Bending and Impact Loading. International Journal of Impact Engineering 2012;43:6-15.

[14] Boudjemai A, Bouanane M, Mankour A, et al. (2013) Thermo-Mechanical Design of Honeycomb Panel with Fully-Potted Inserts used for Aircraft Design. Proceedings of the $16^{\text {th }}$ International conference on recent advances in space technologies, Istanbul, Turkey, 12-14 June 2013, DOI: 10.1109/RAST.2013.6581238.

[dataset][15] Olga A. Ganilova, Matthew P. Cartmell, and Andrew Kiley, Open Data for the paper 'Experimental investigation of the thermoelastic performance of an aerospace aluminium honeycomb composite panel', University of Strathclyde, 2019, https://doi.org/10.15129/28a67ac3-0daf-4c8d-81c7-3af6a847c211

[16] Santos Silva AC, Sebastian CM, Lambros J, Patterson EA. High temperature modal analysis of a non-uniformly heated rectangular plate: Experiments and simulations. Journal of Sound and Vibration 2019;443:397-410.

[17] Zhao X, Chen T, Wang S. Effect of NiTi content and test temperature on mechanical behaviours of NiTi-PU composites. International Journal of Lightweight Materials and Manufacture 2018;1:215-218.

[18] De Matteis G, Brando G, Mazzolani FM. Hysteretic behaviour of bracing-type pure aluminium shear panels by experimental tests. Earthquake Engineering and Structural Dynamics 2010;40:1143-1162. 
[19] Krasnobrizha A, Rozycki P, Cosson P, et al. Modelling the hysteresis composite behaviour using an elasto-plasto-damage model with fractional derivatives. HAL archives-ouvertes, 2015. Available at: https://hal.archives-ouvertes.fr/hal-01240728 (accessed 13 August 2020). 


\section{Figures}

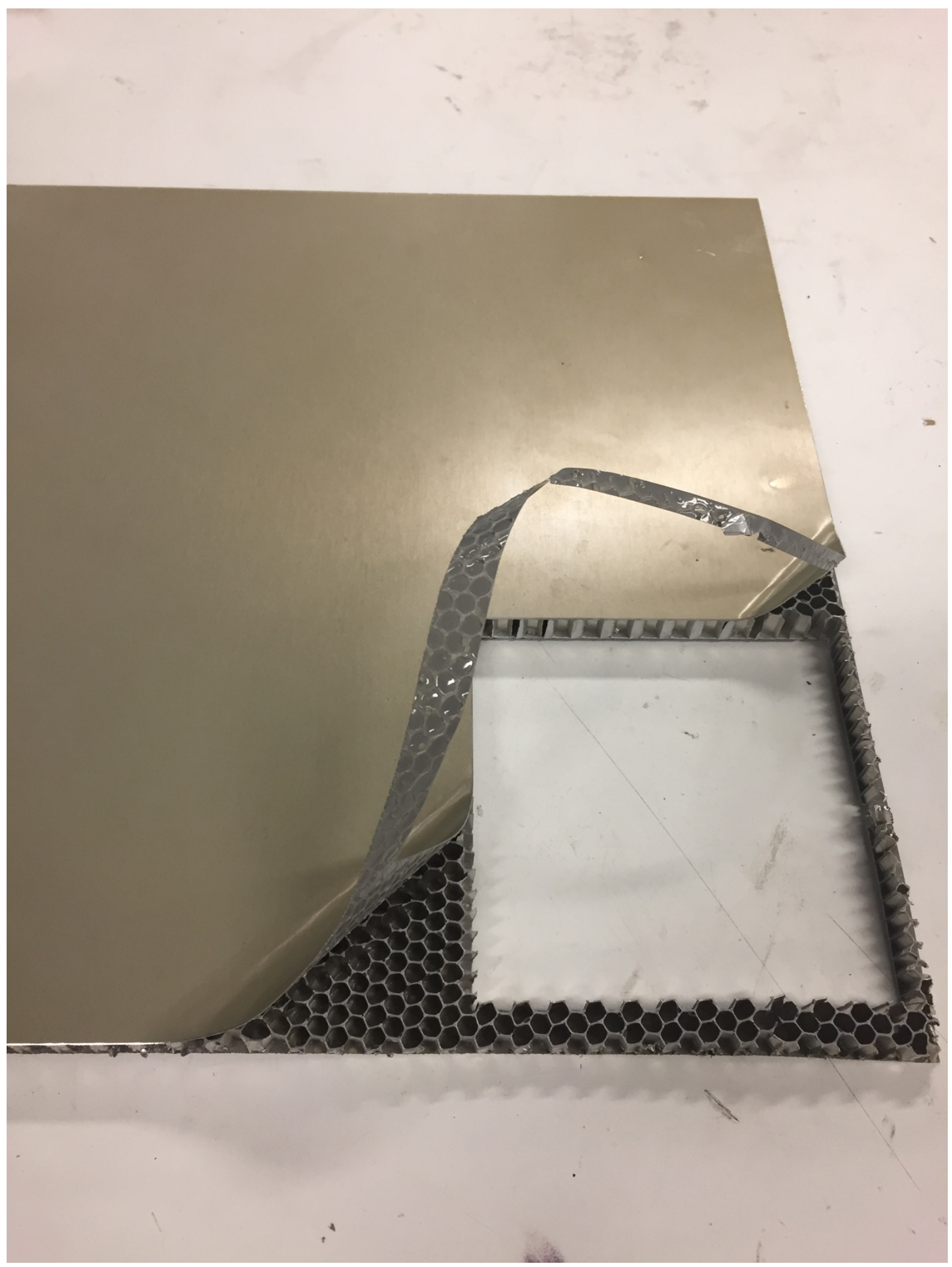

Figure 1 


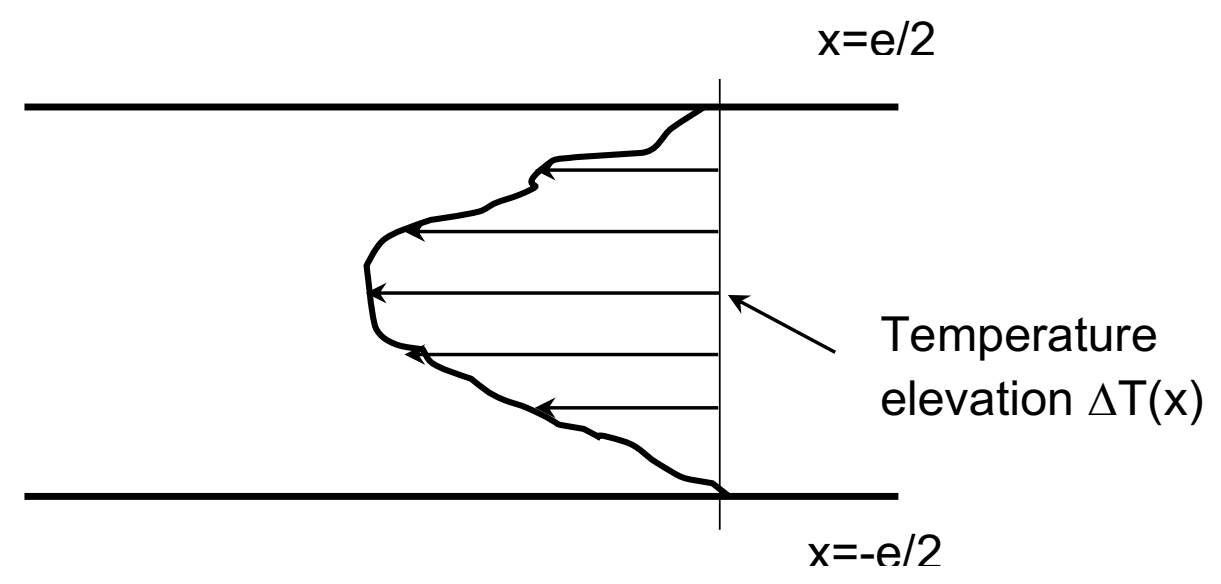

Figure 2 


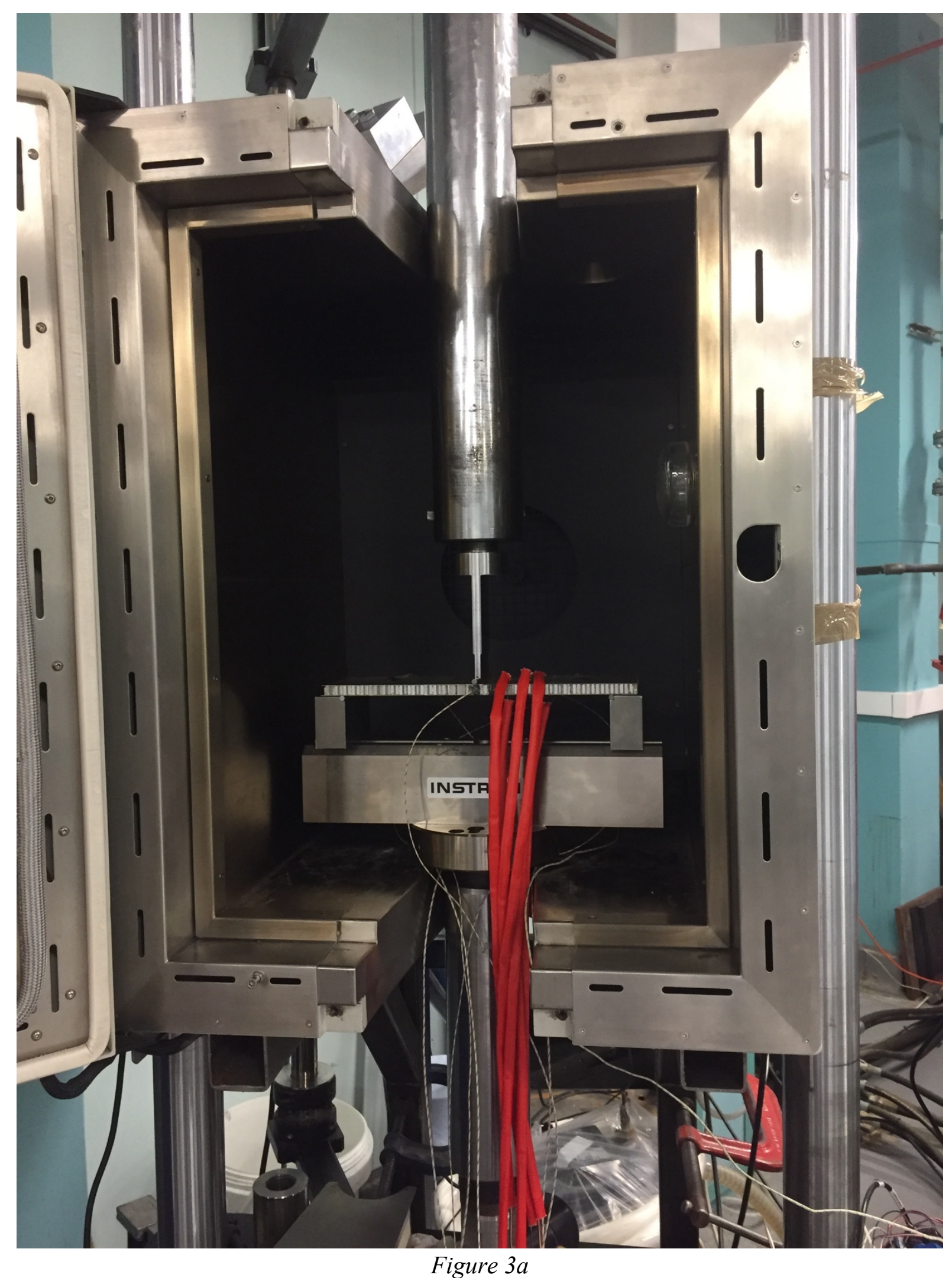




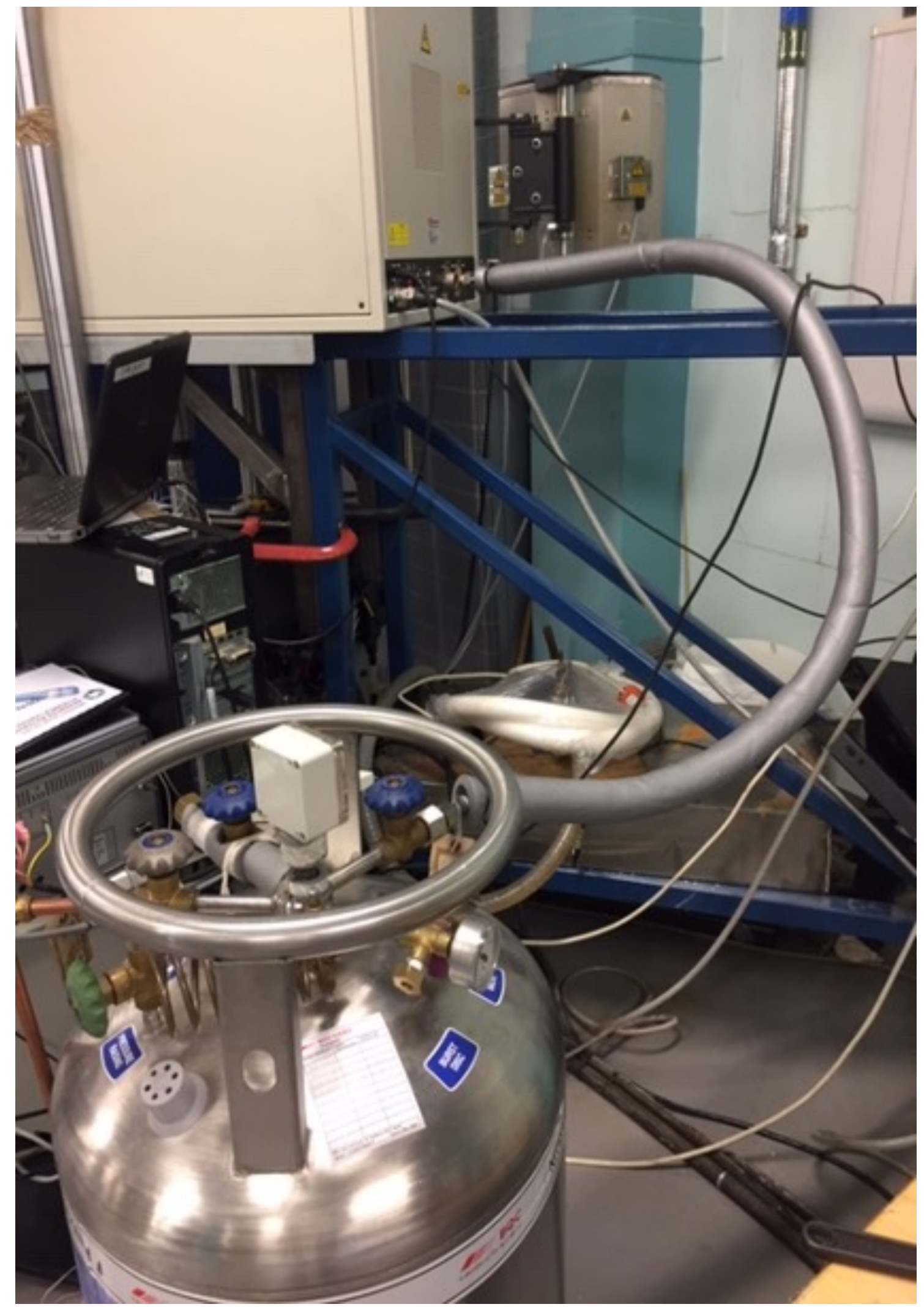

Figure $3 b$ 


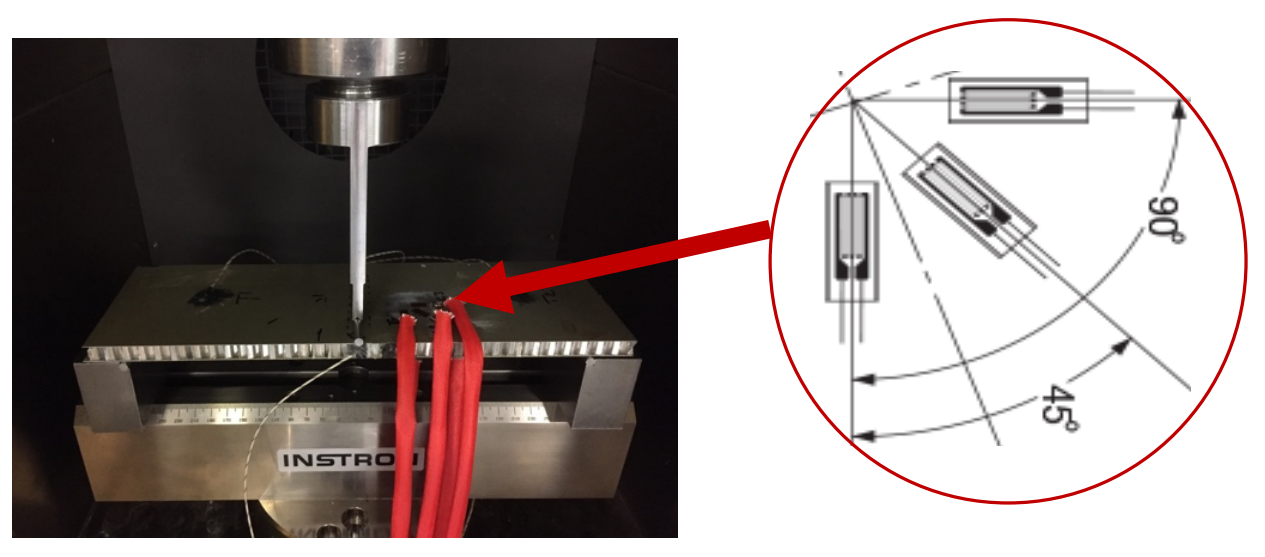

Figure 4
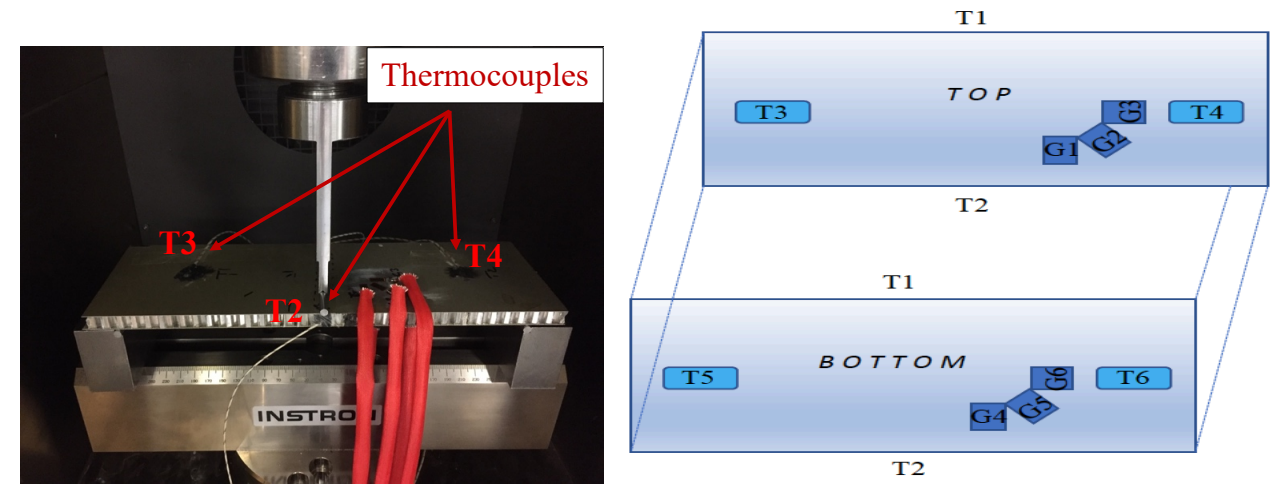

Figure 5 


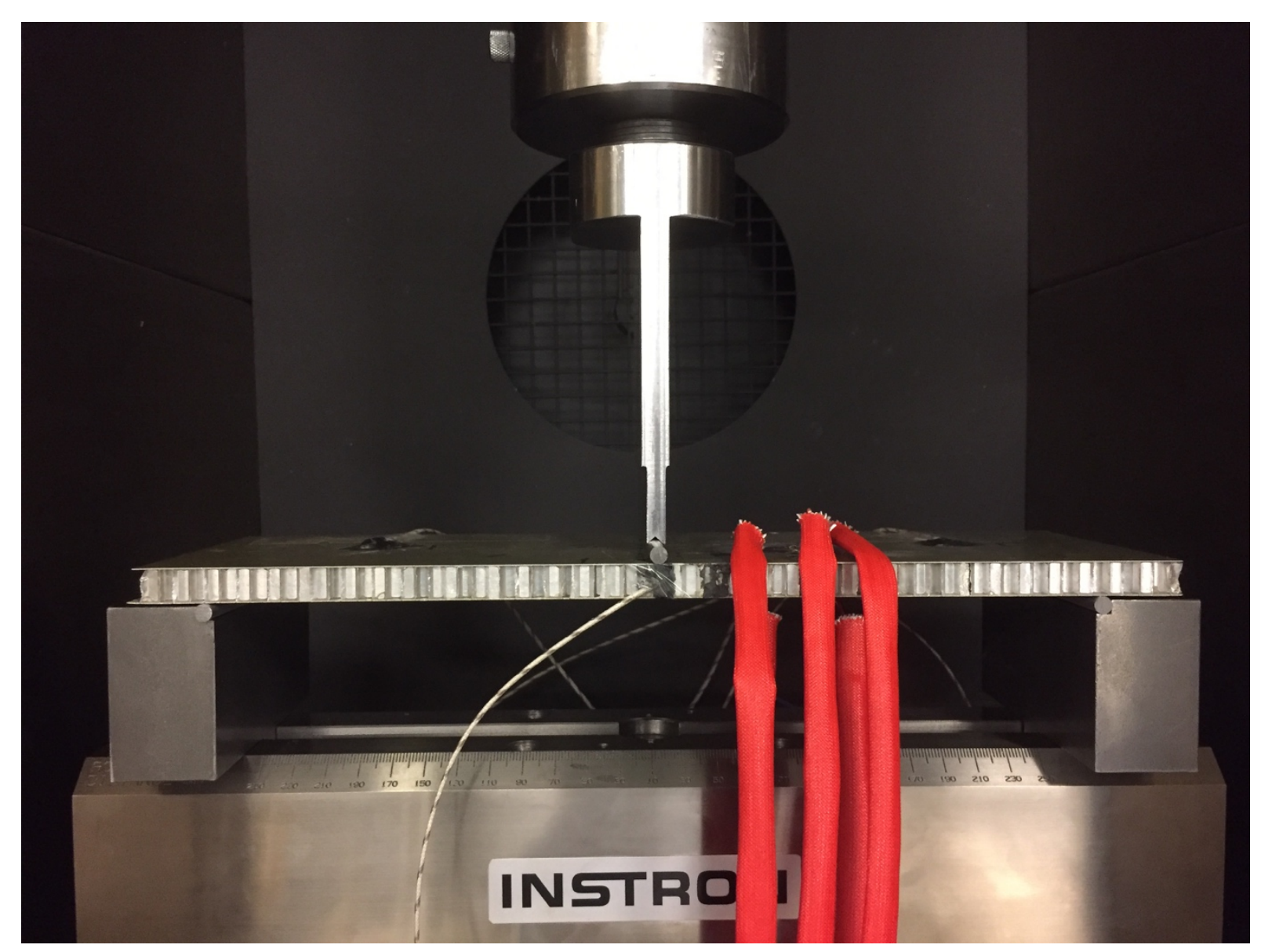

Figure 6 


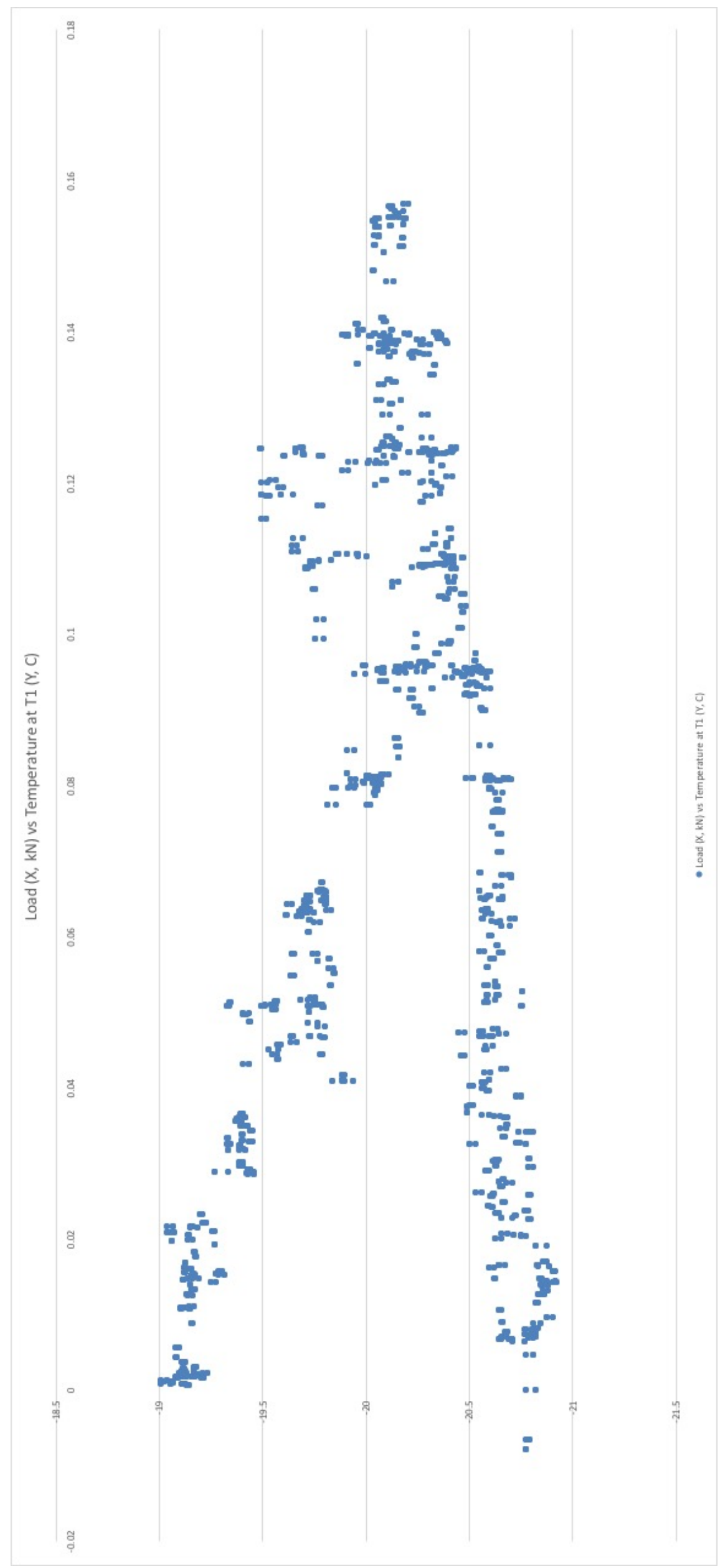

Figure $7 a$ 


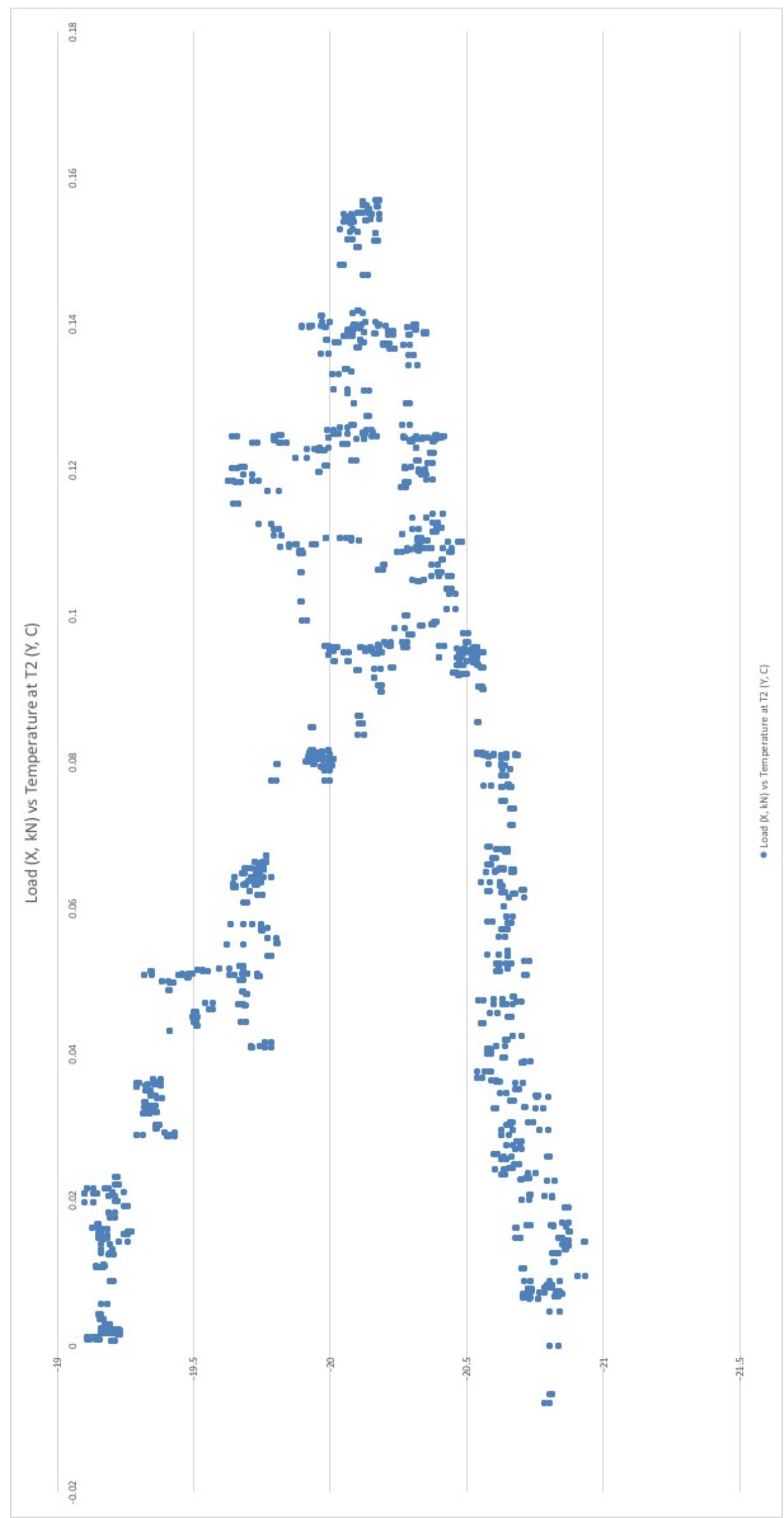

Figure 7b 


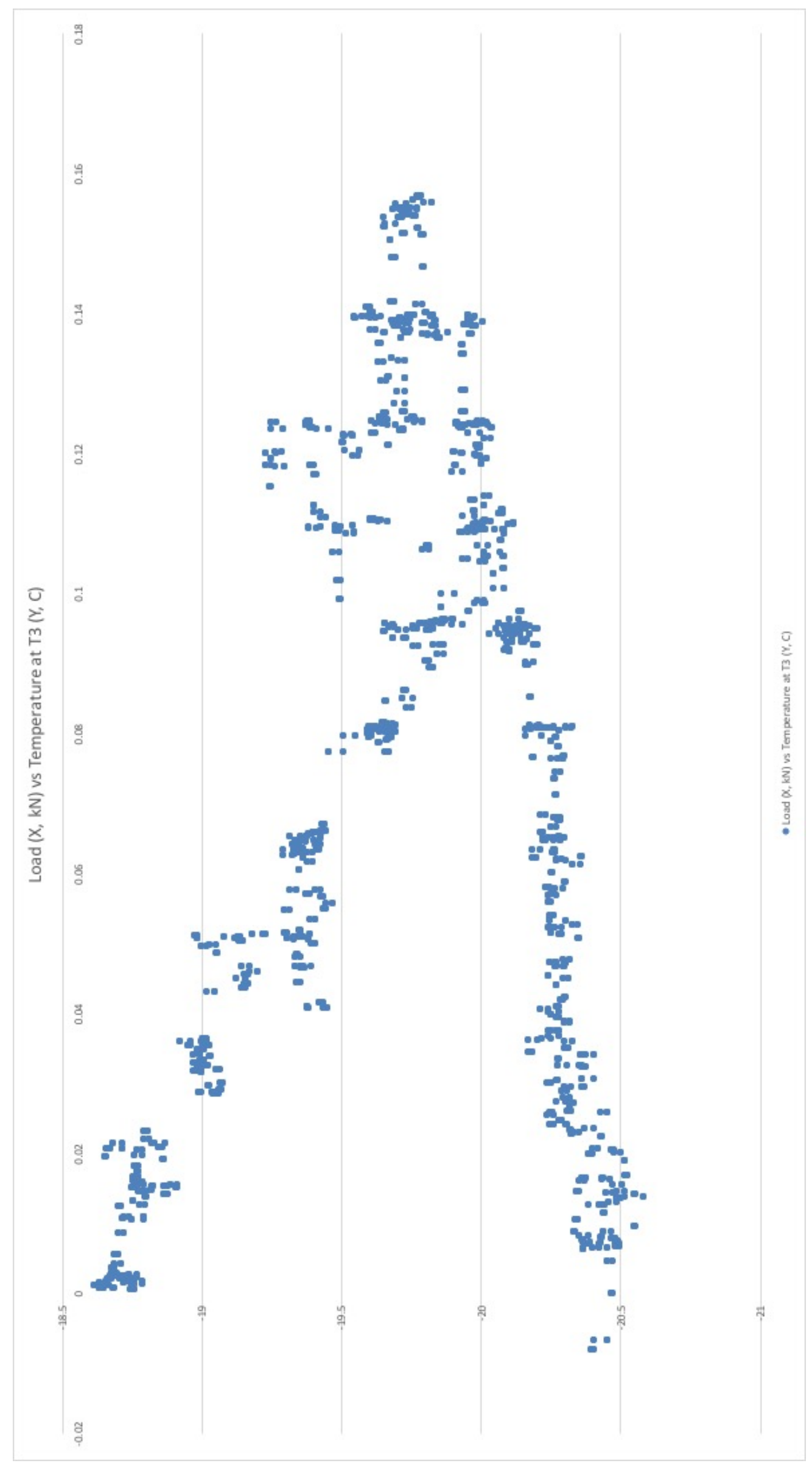

Figure 7c 


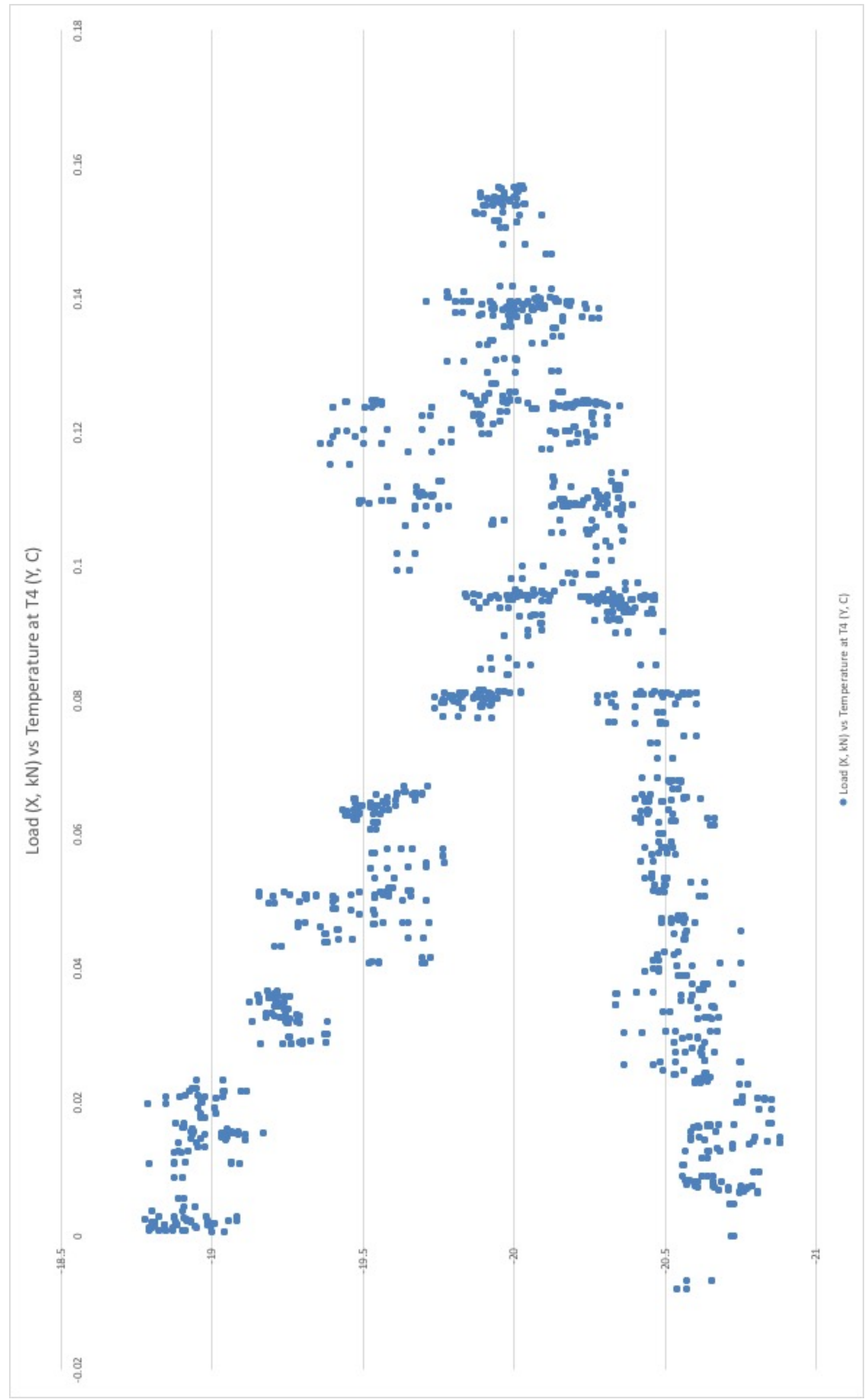

Figure 7d 


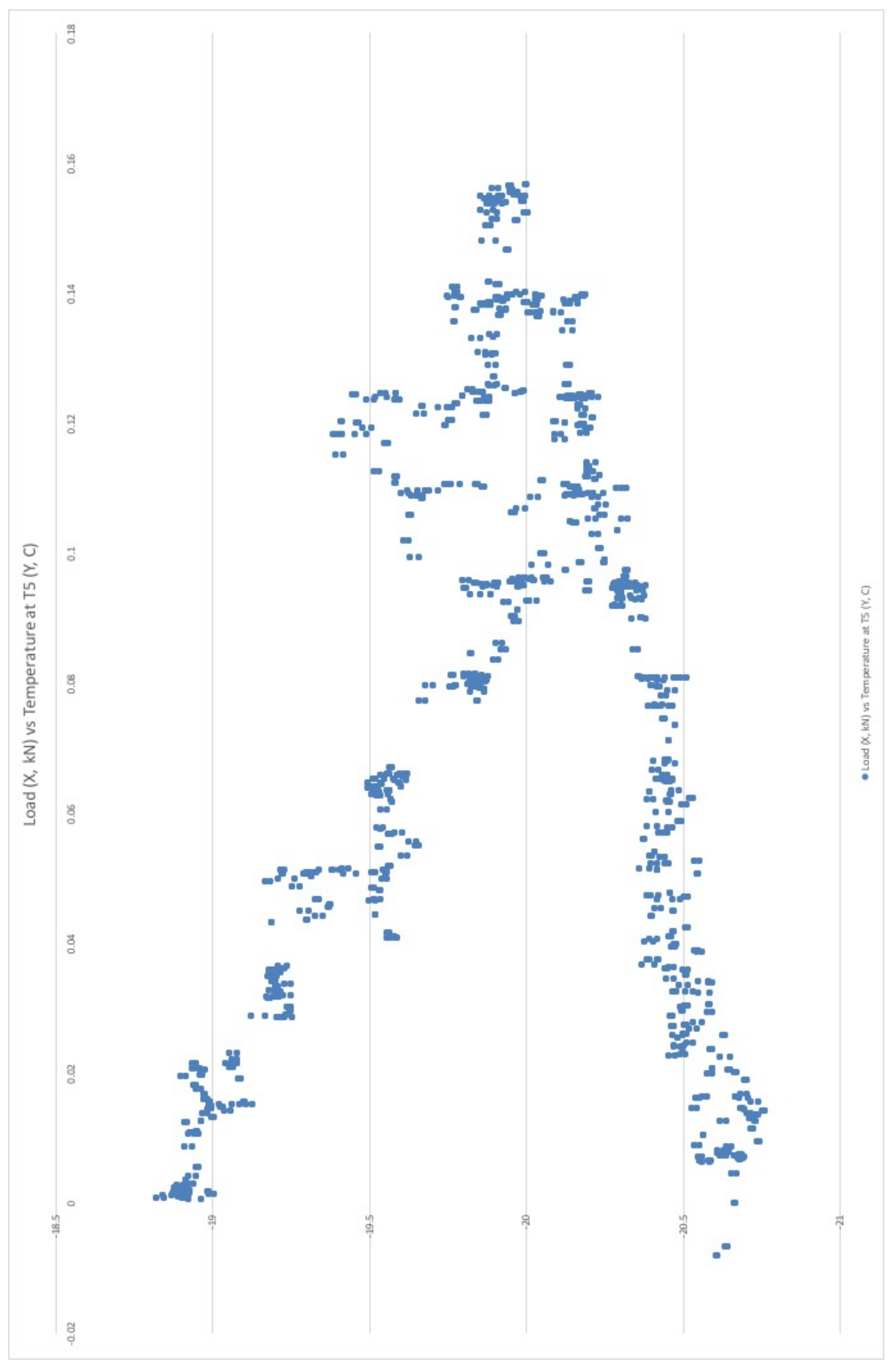

Figure 7e 


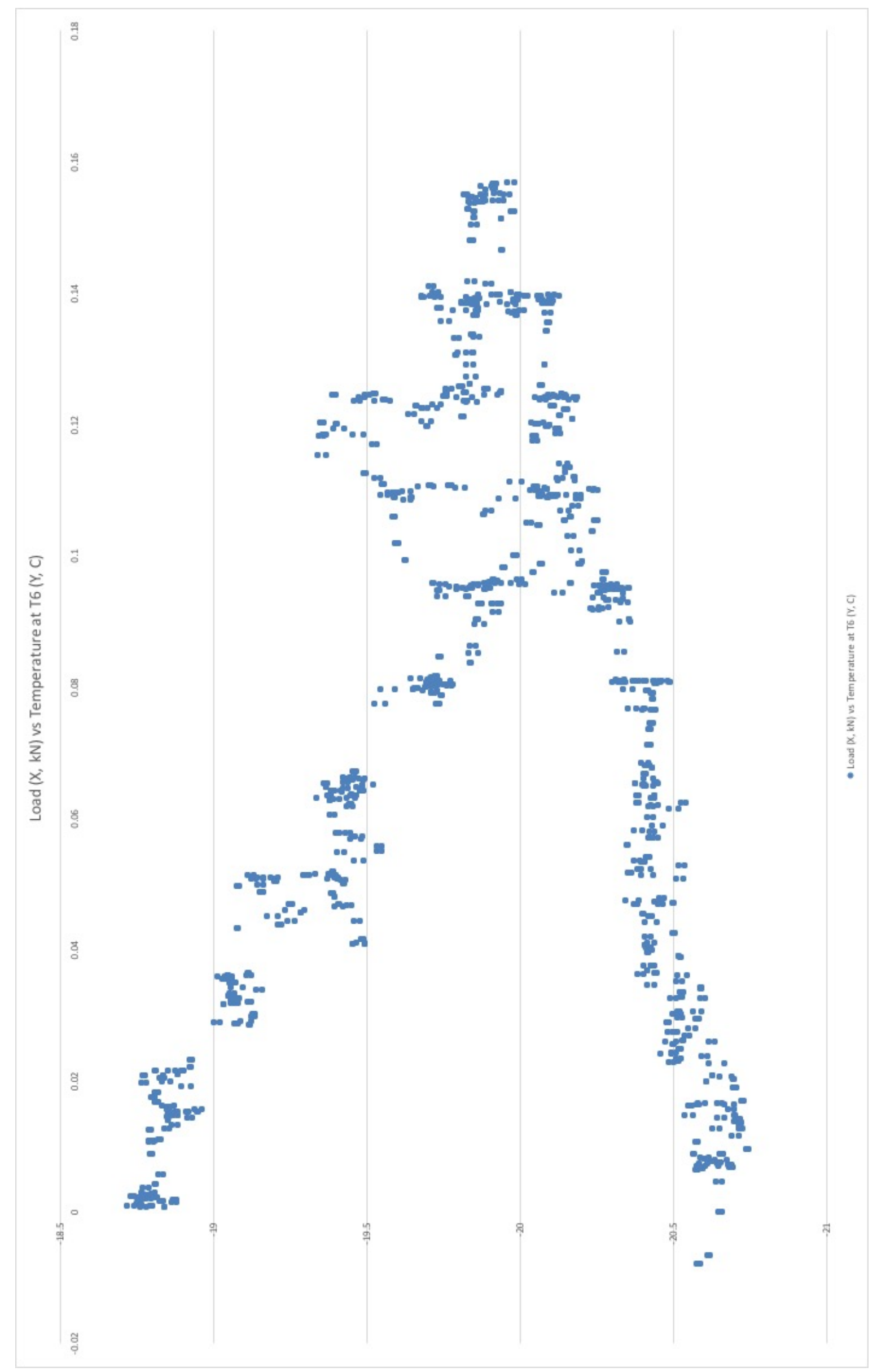

Figure $7 f$ 


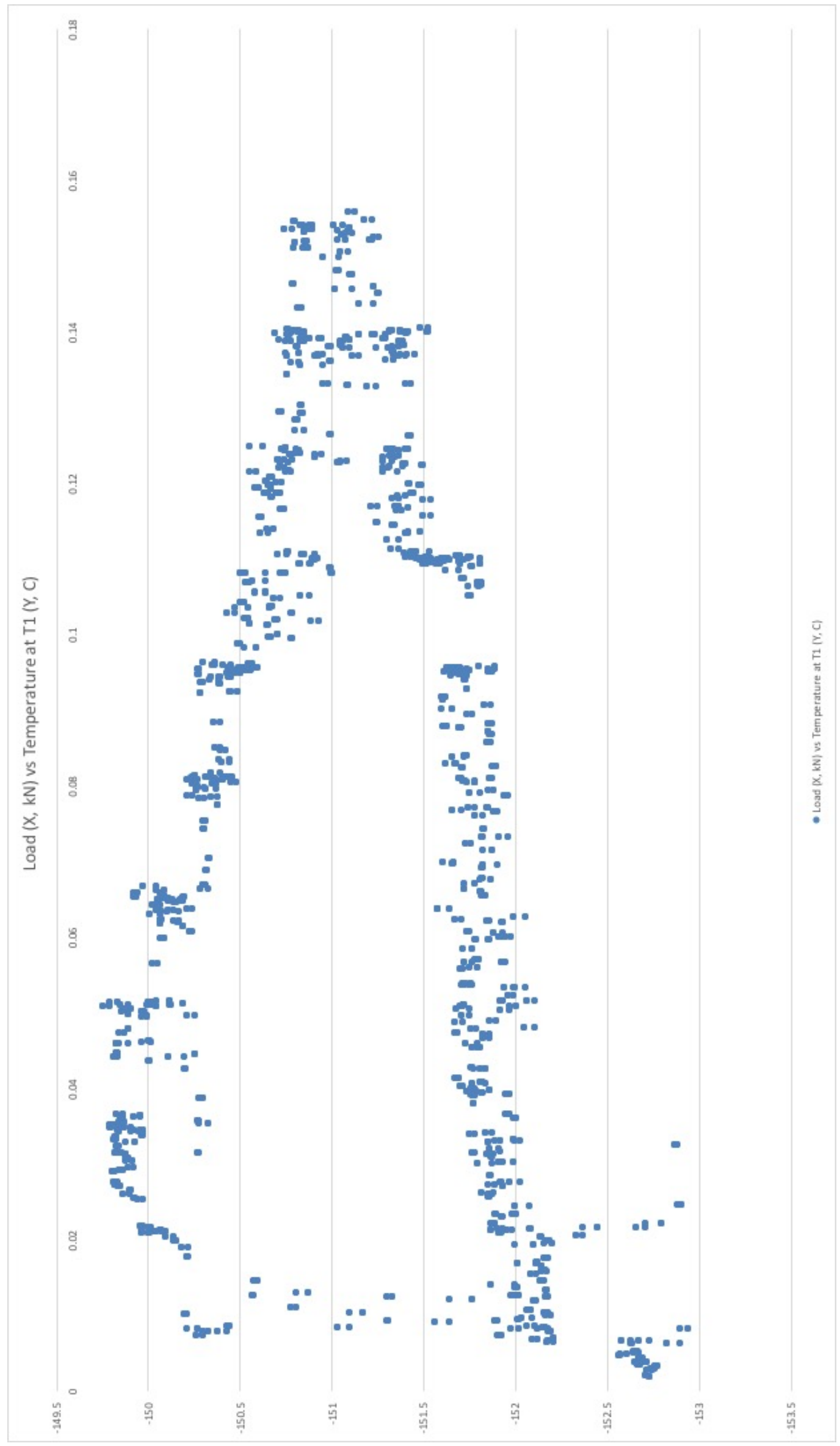

Figure $8 a$ 


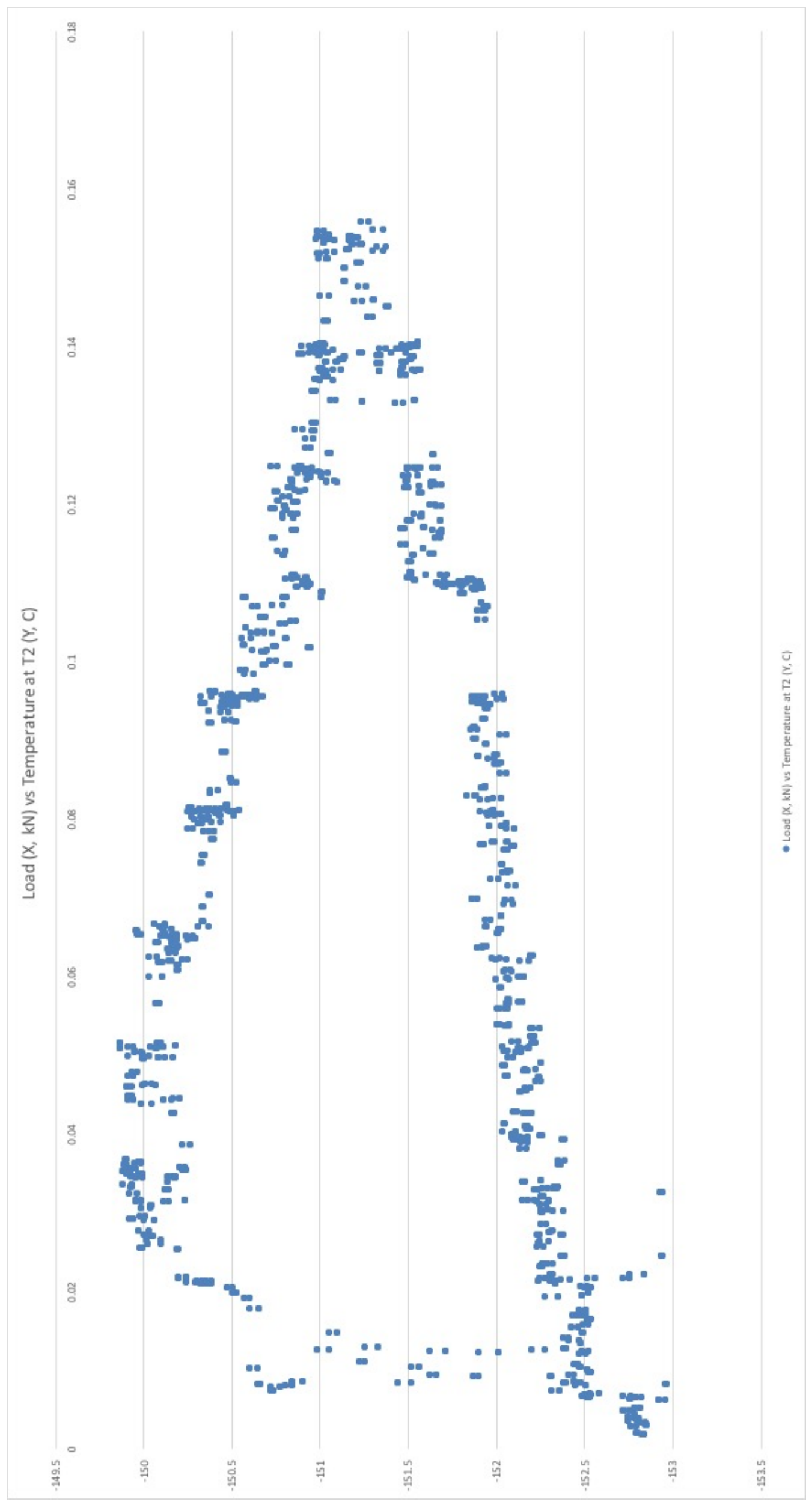

Figure $8 b$ 


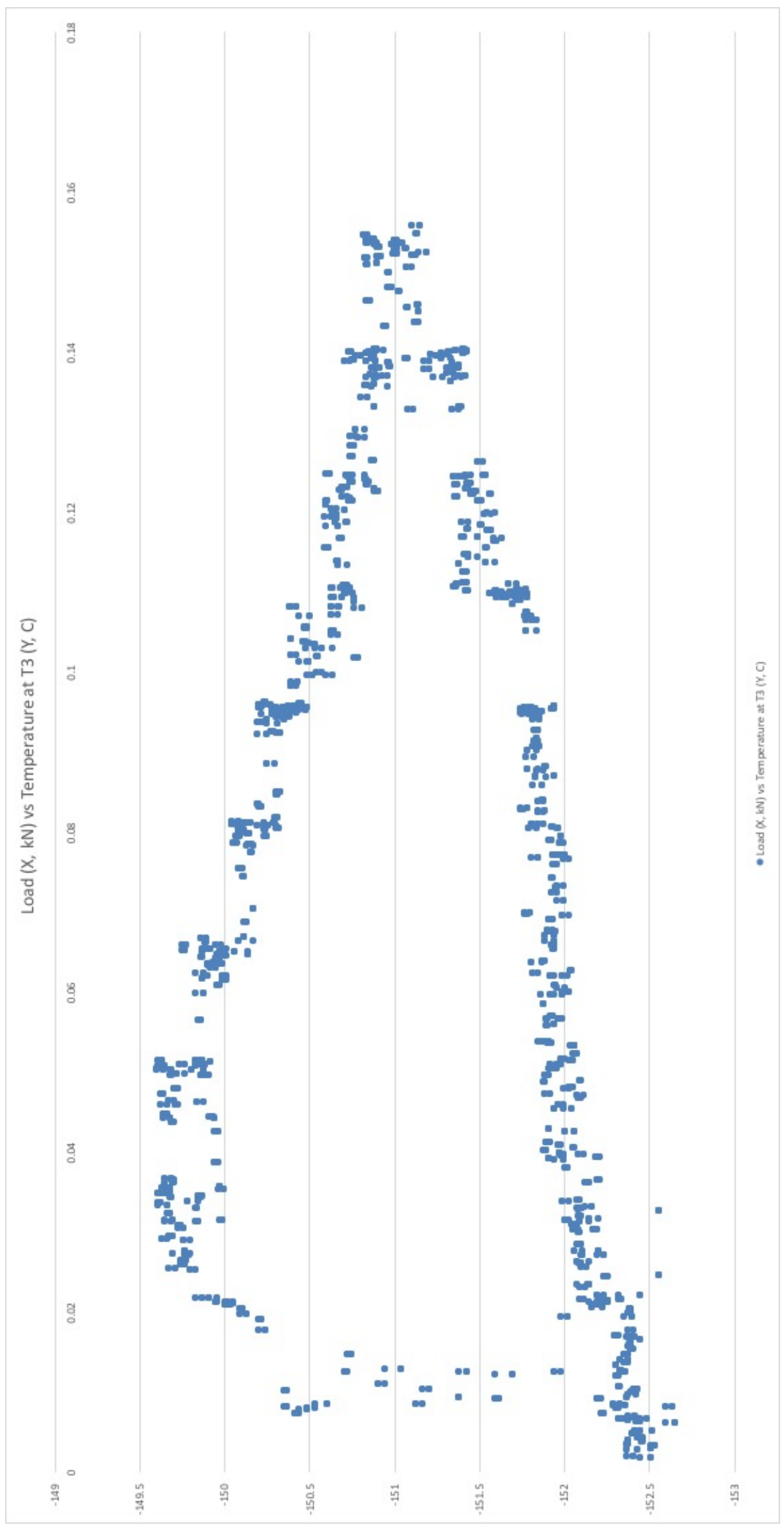

Figure 8c 


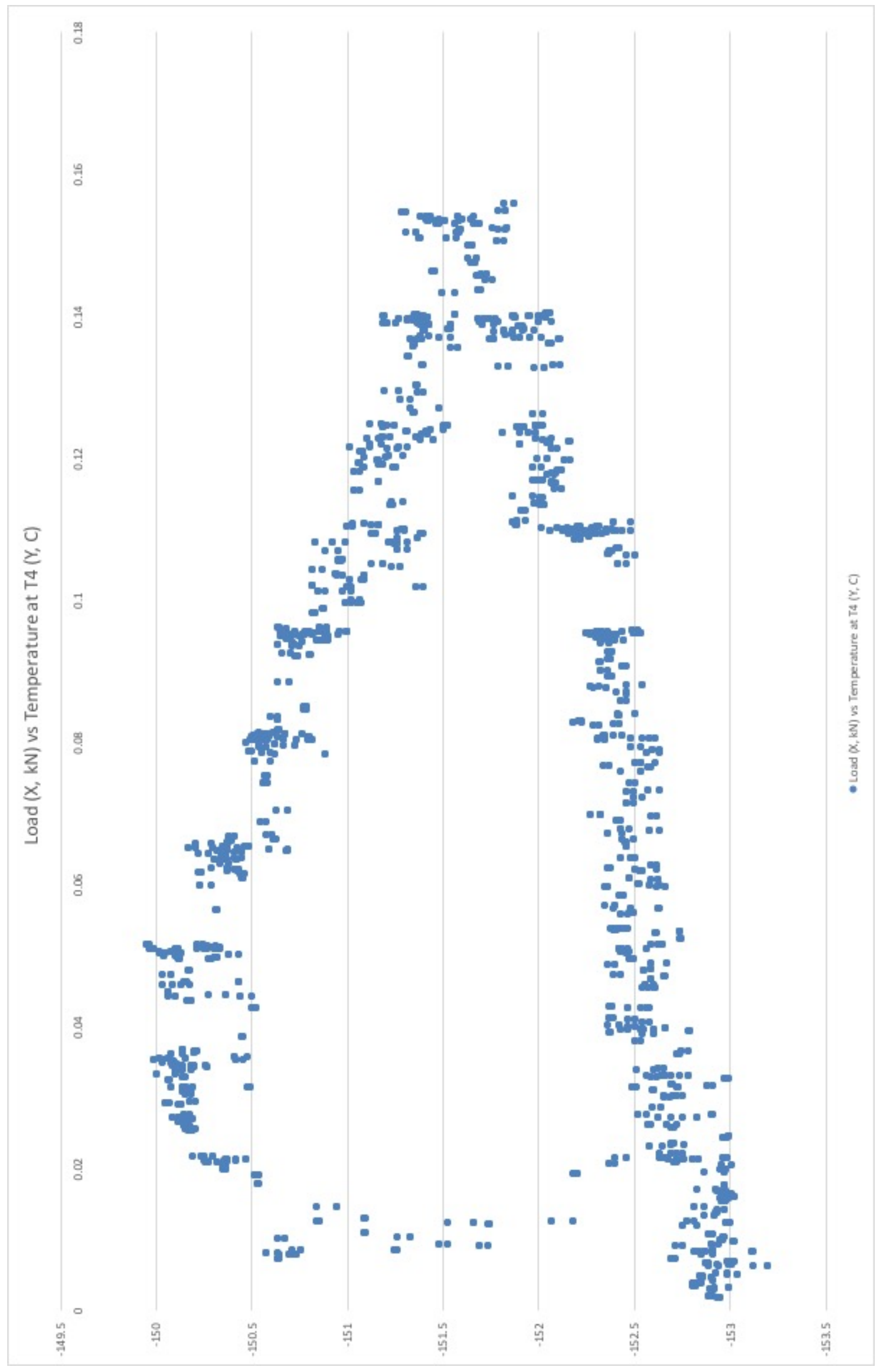

Figure $8 d$ 


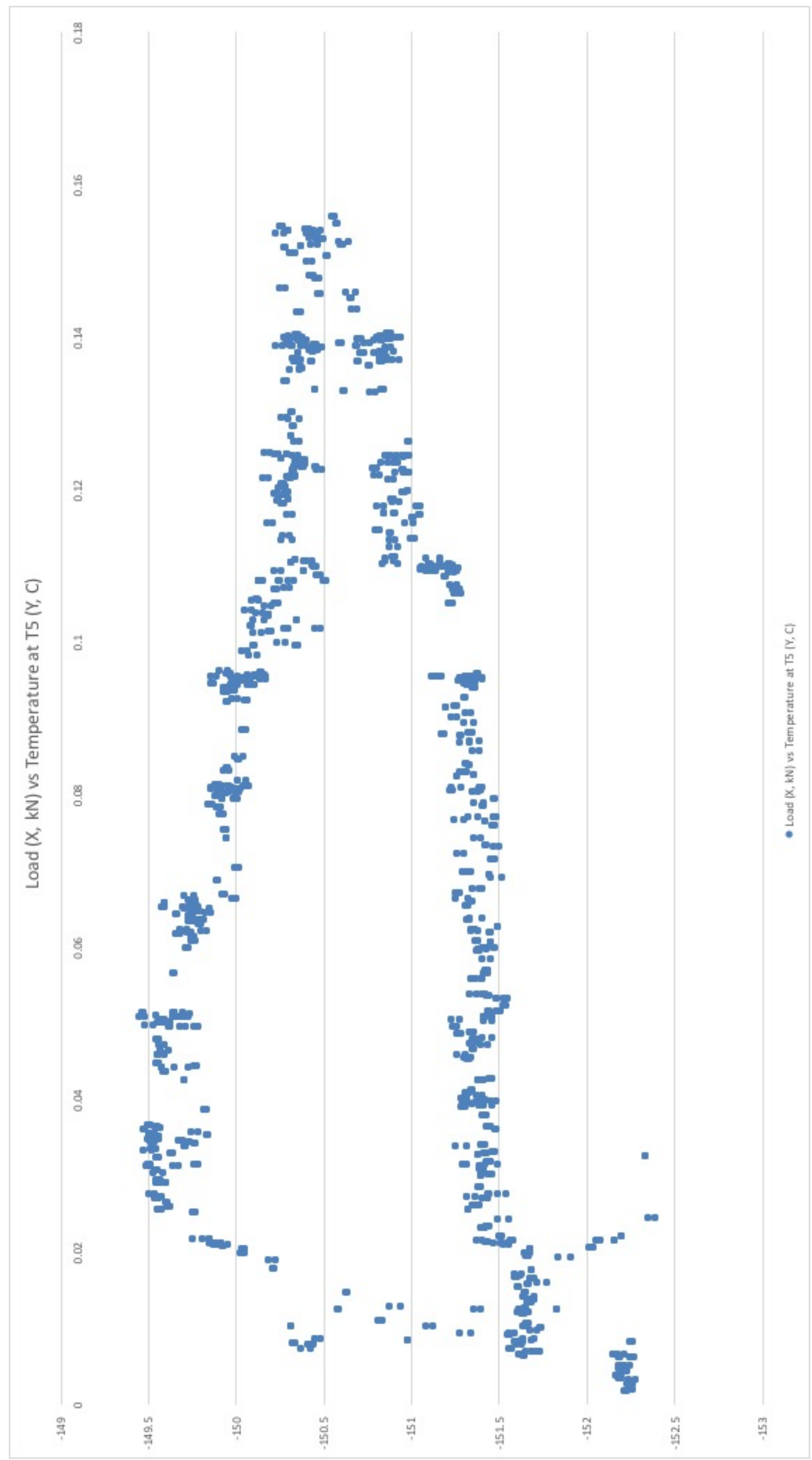

Figure 8e 


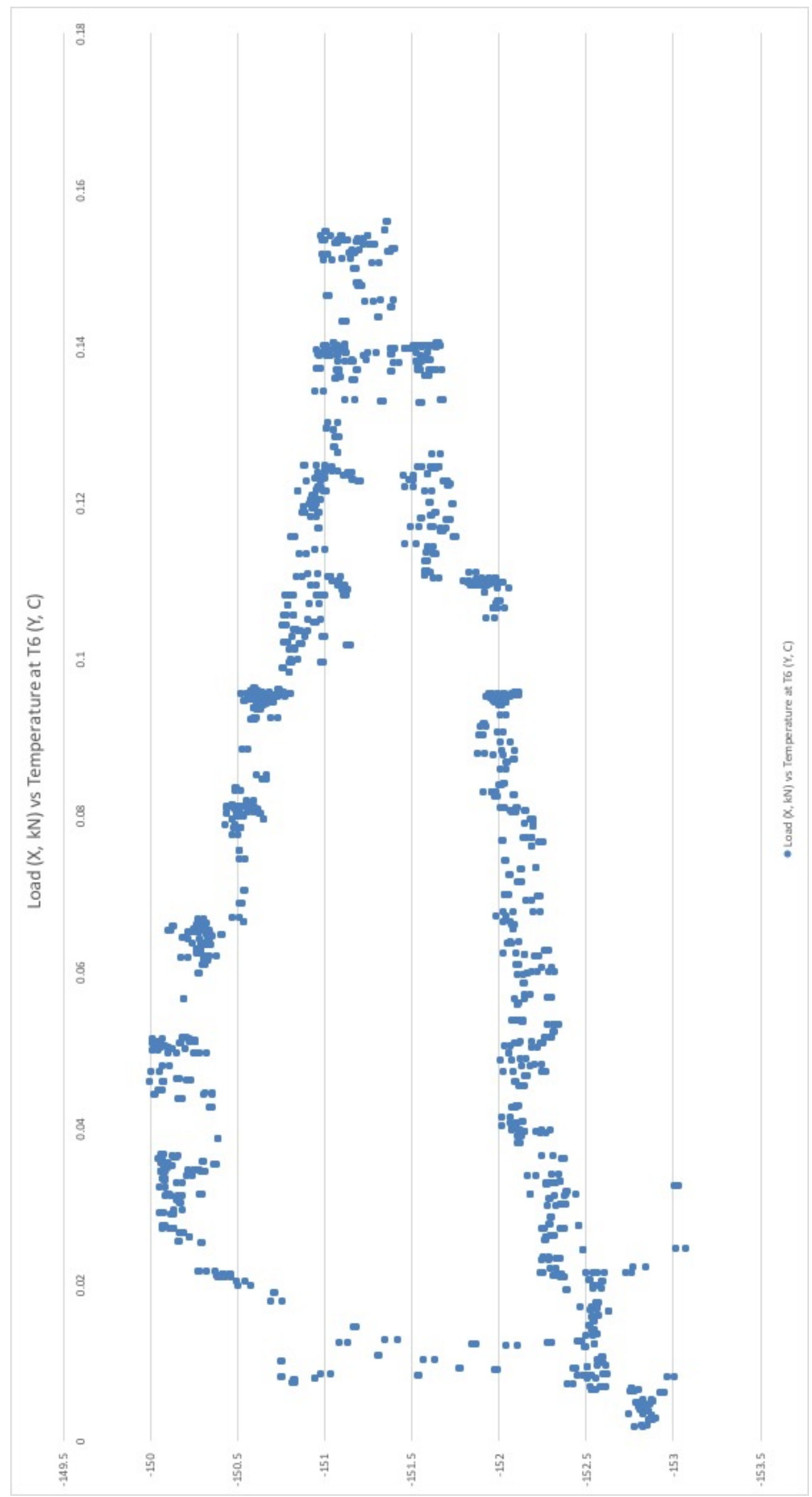

Figure $8 f$ 


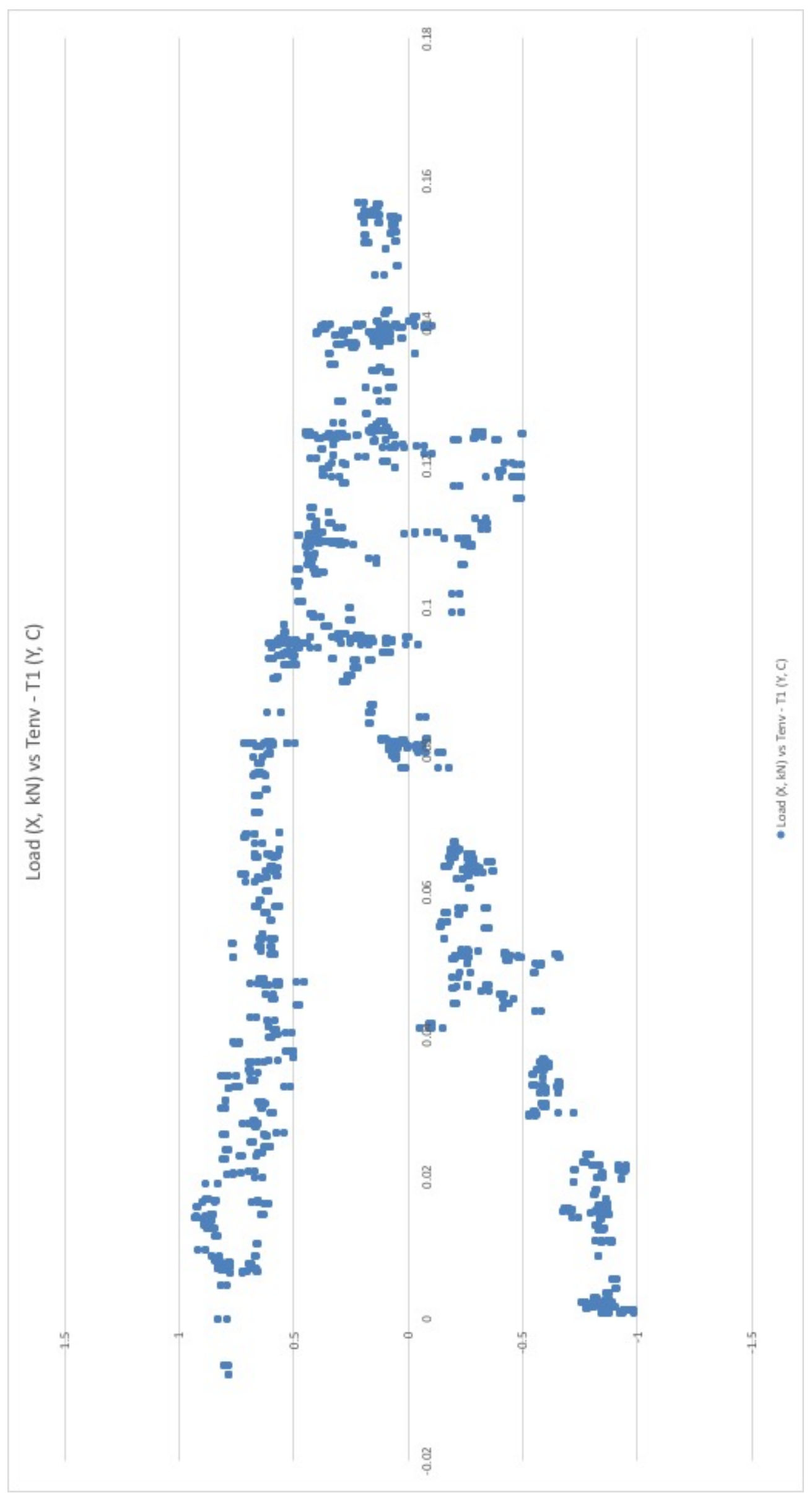

Figure $9 a$ 


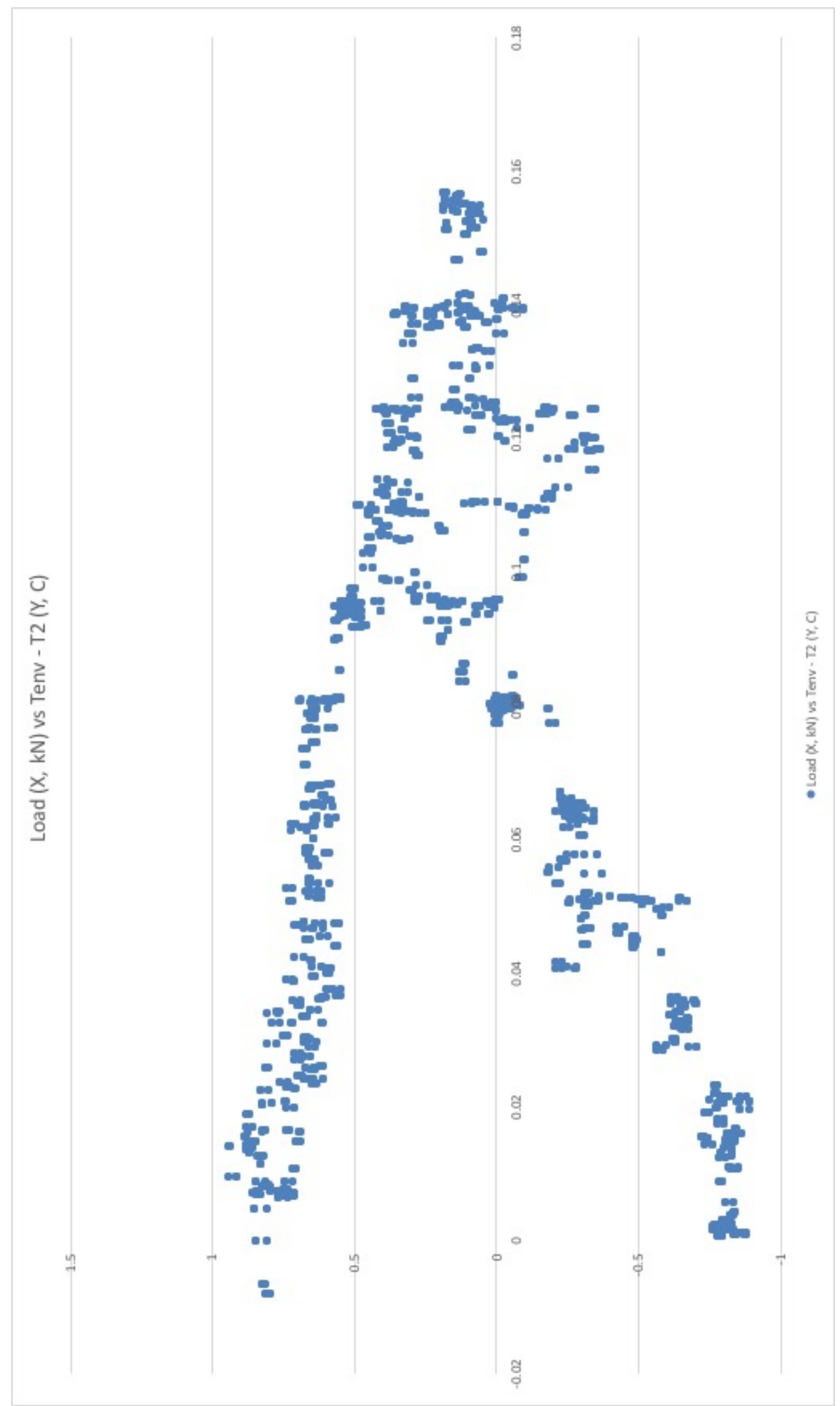

Figure $9 b$ 


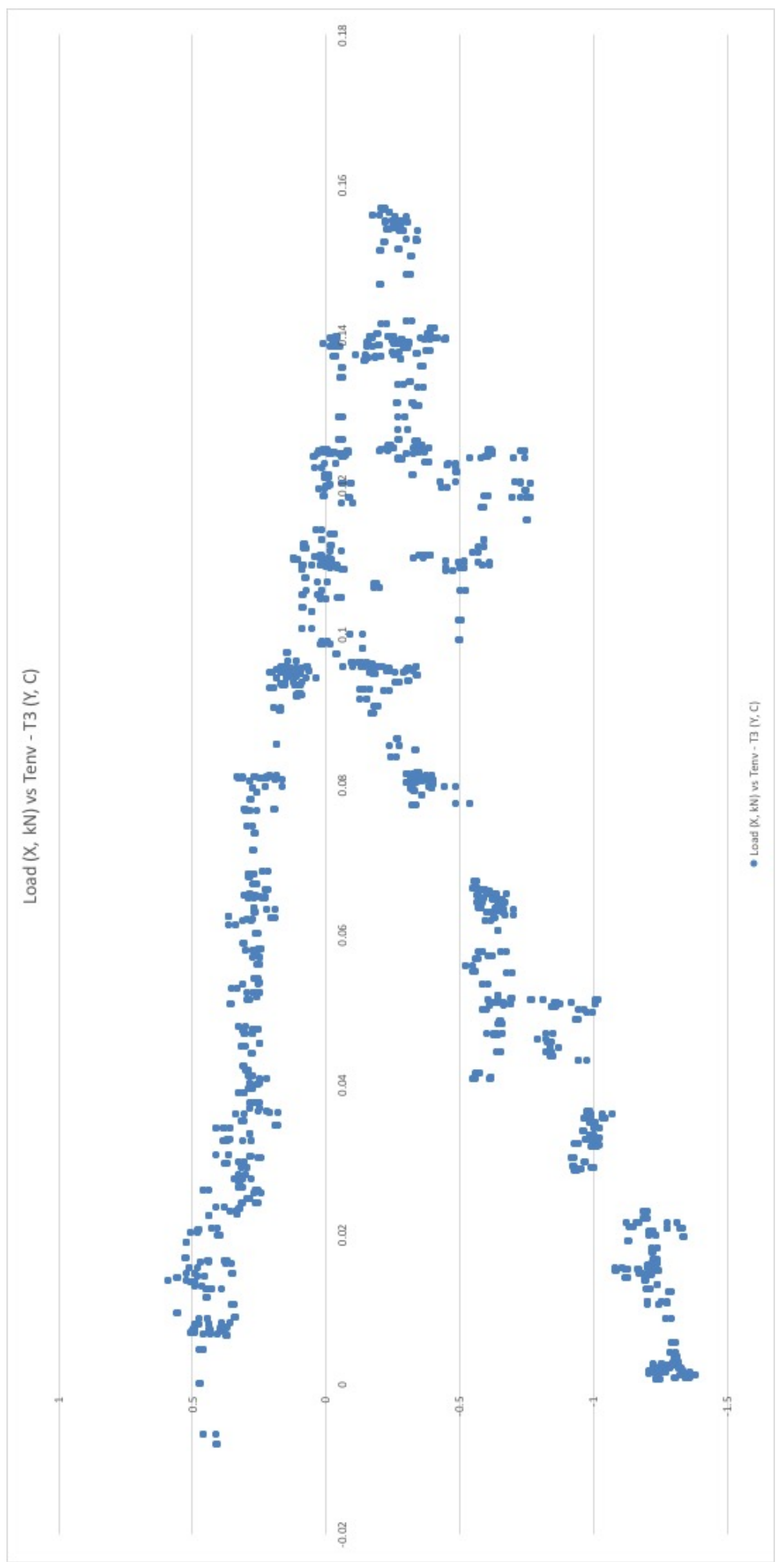

Figure $9 c$ 


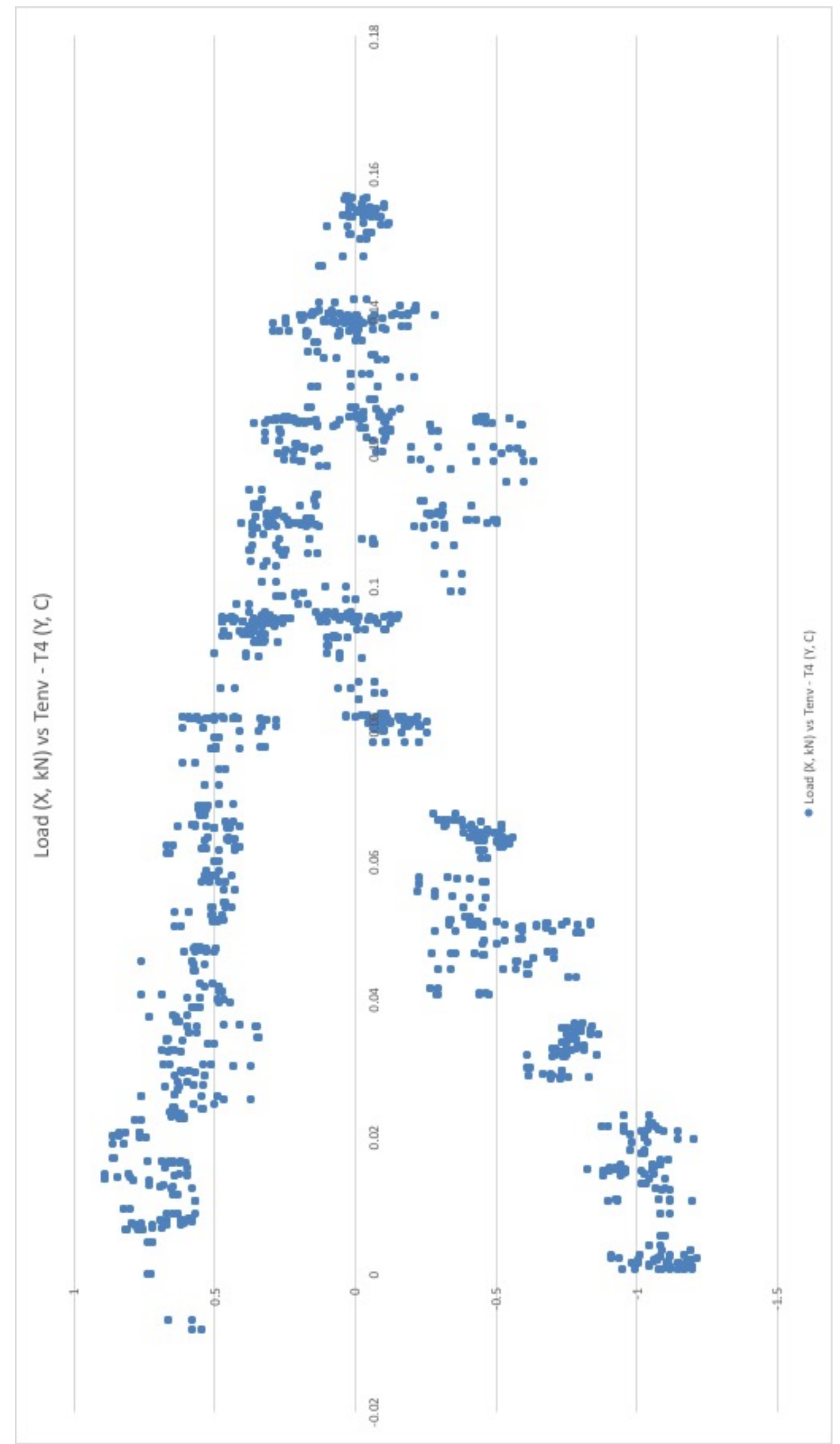

Figure 9d 


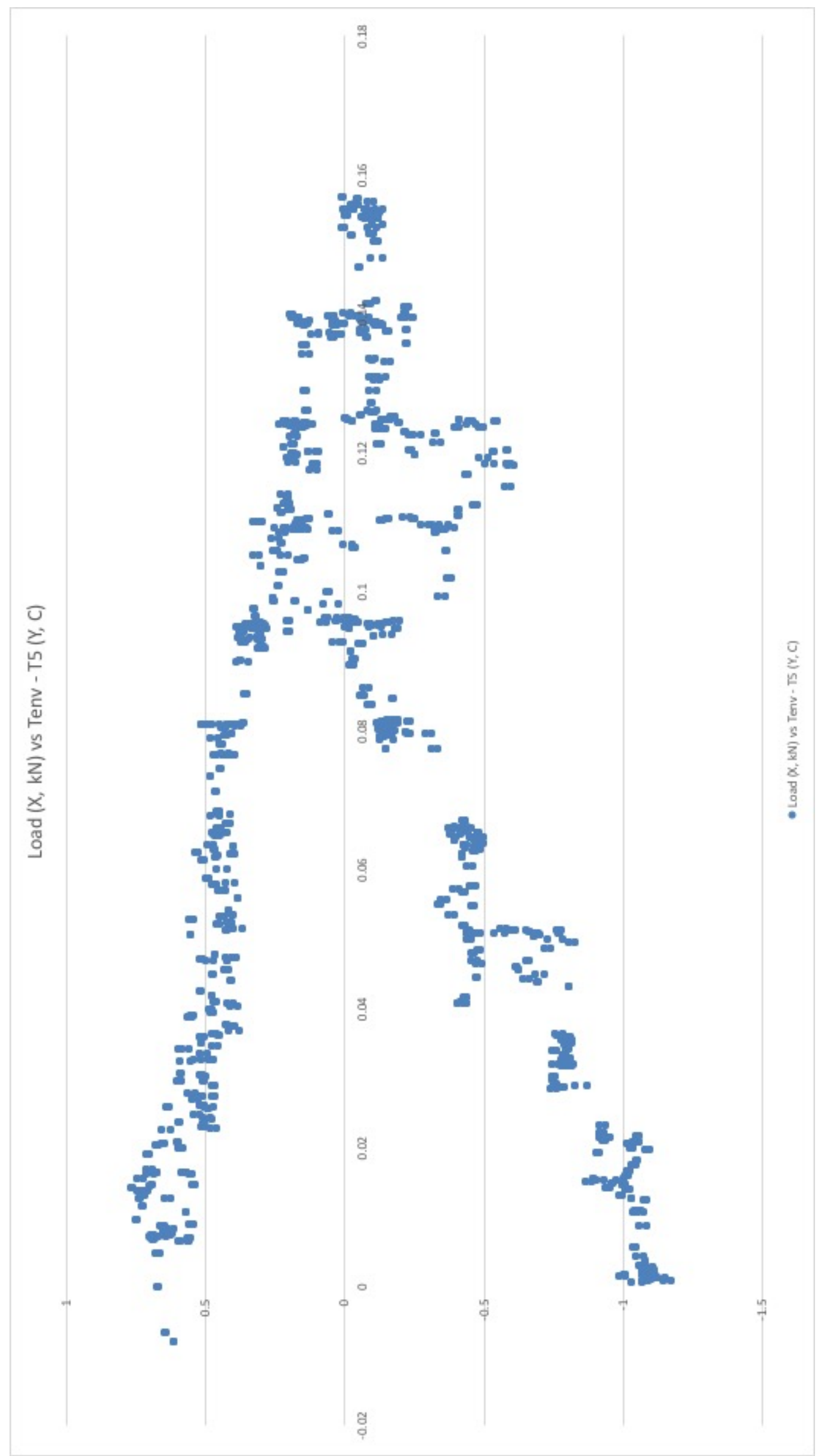

Figure 9e 


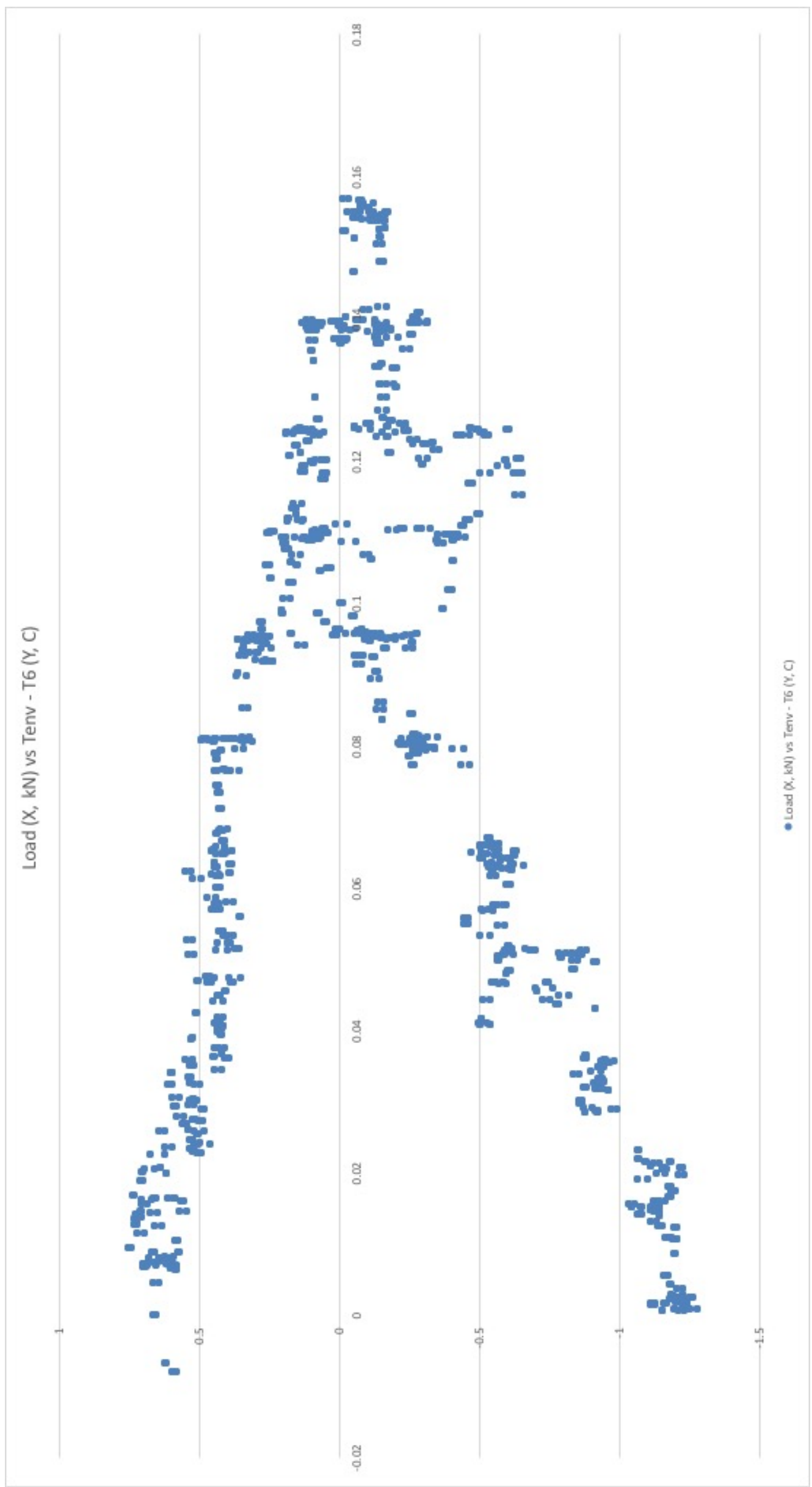

Figure $9 f$ 


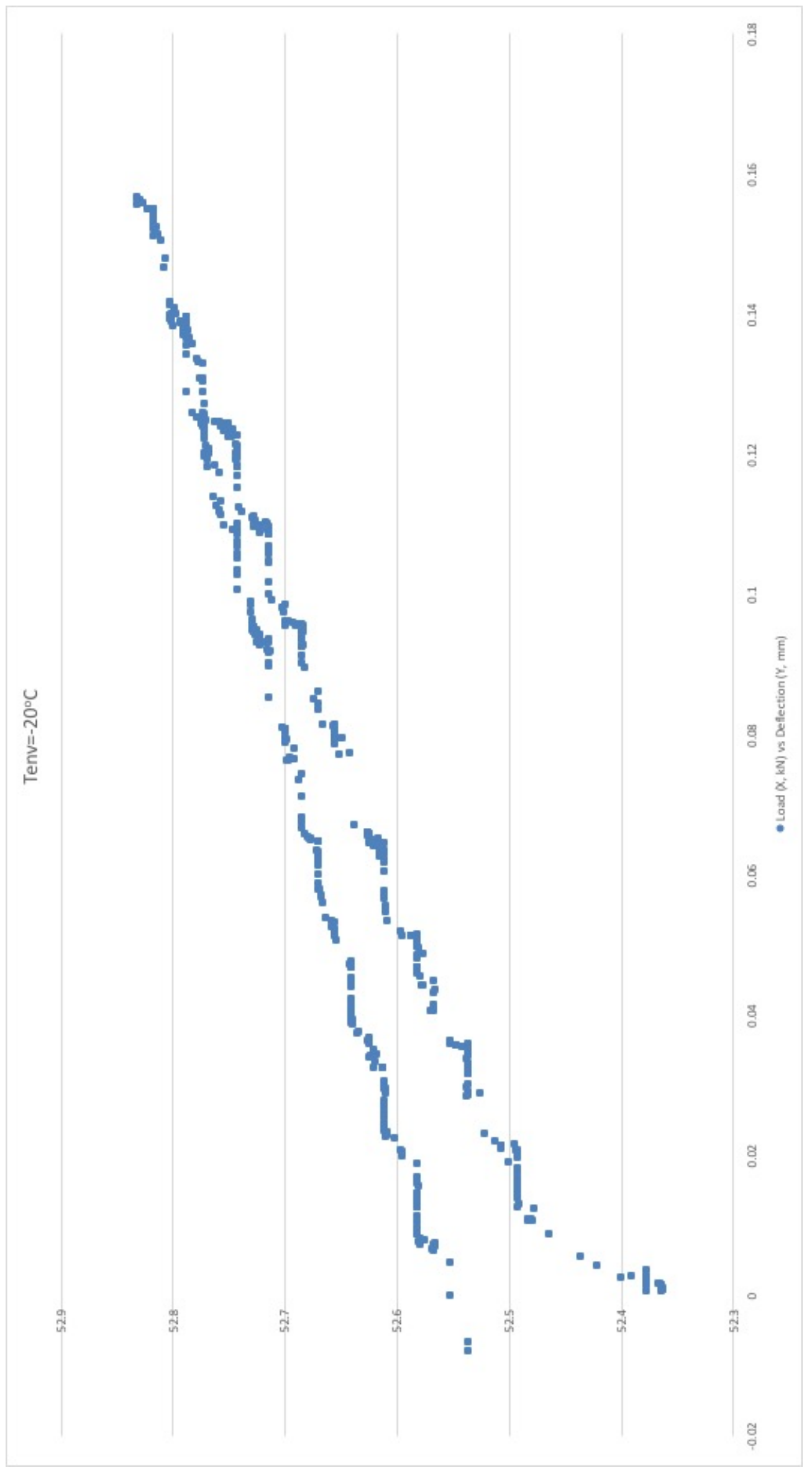

Figure 10a 


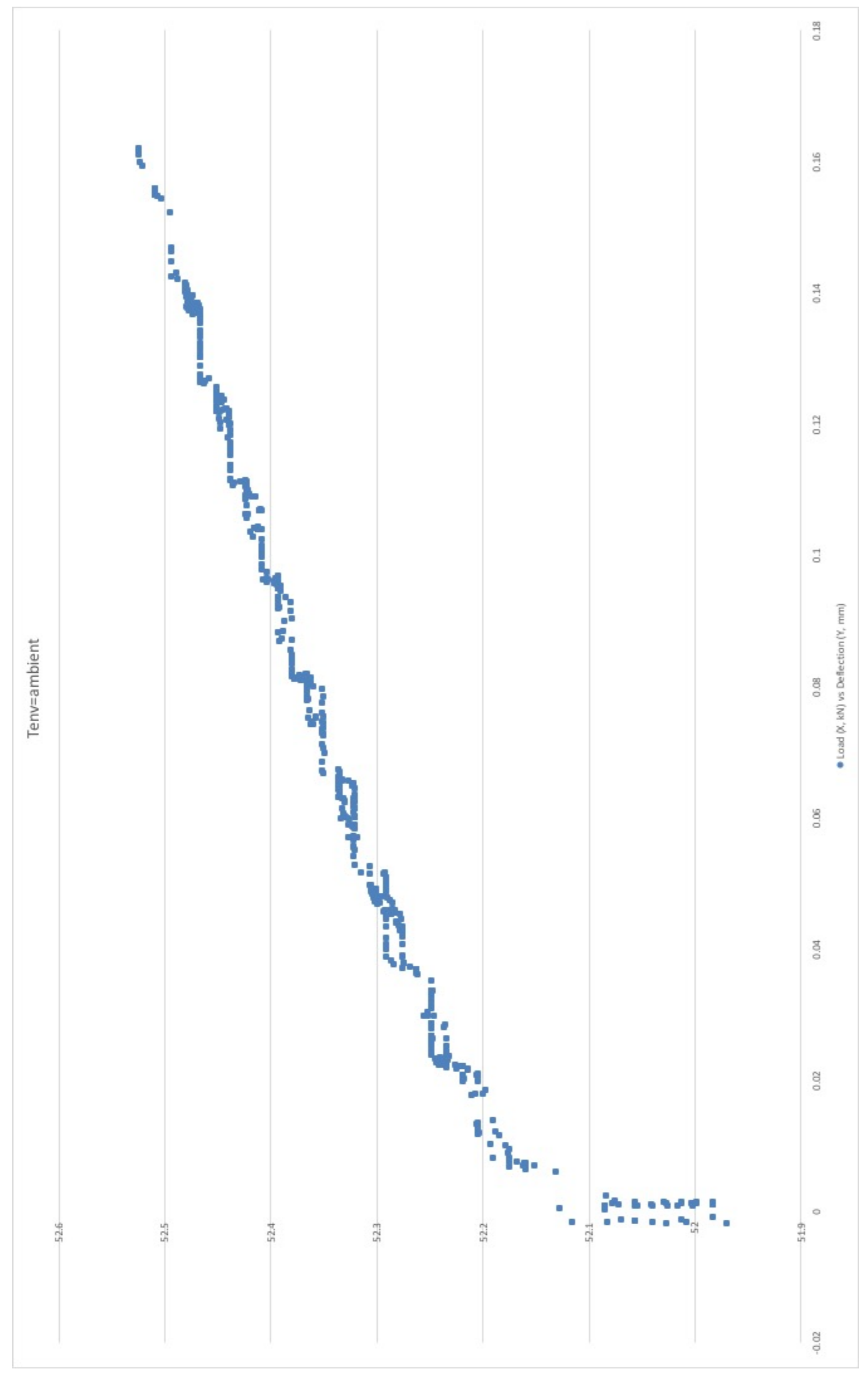

Figure $10 b$ 


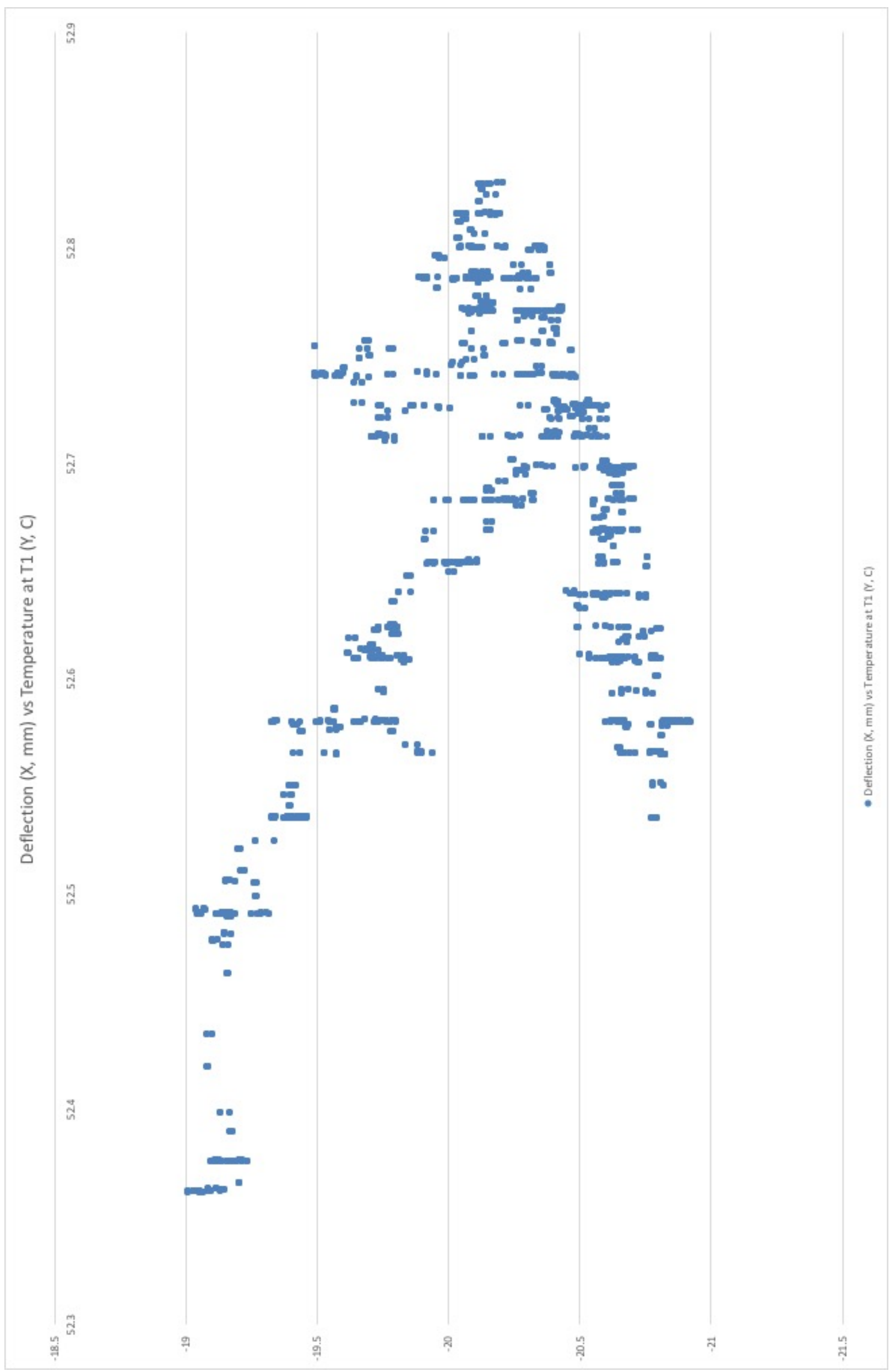

Figure 11a 


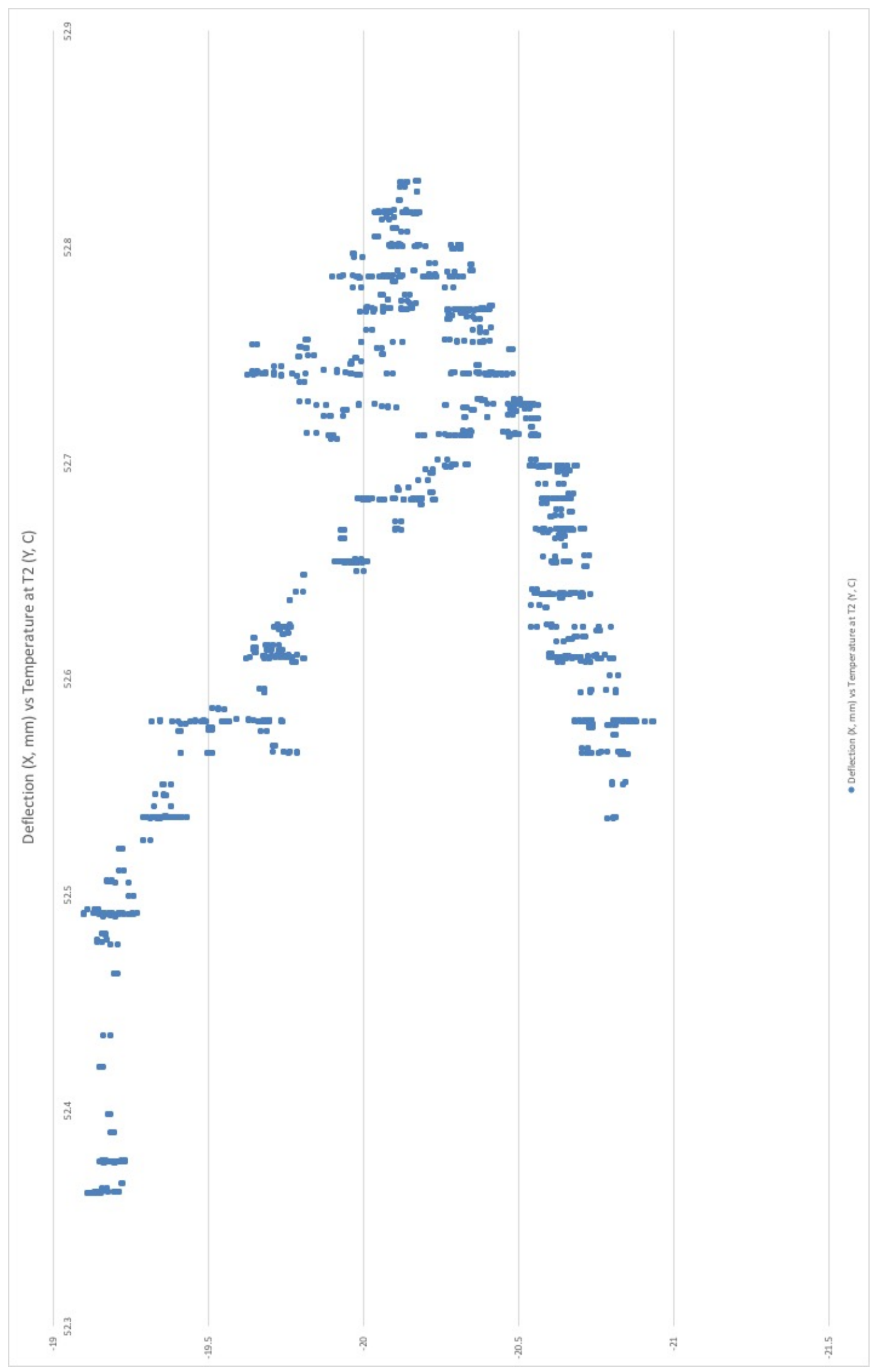

Figure $11 b$ 


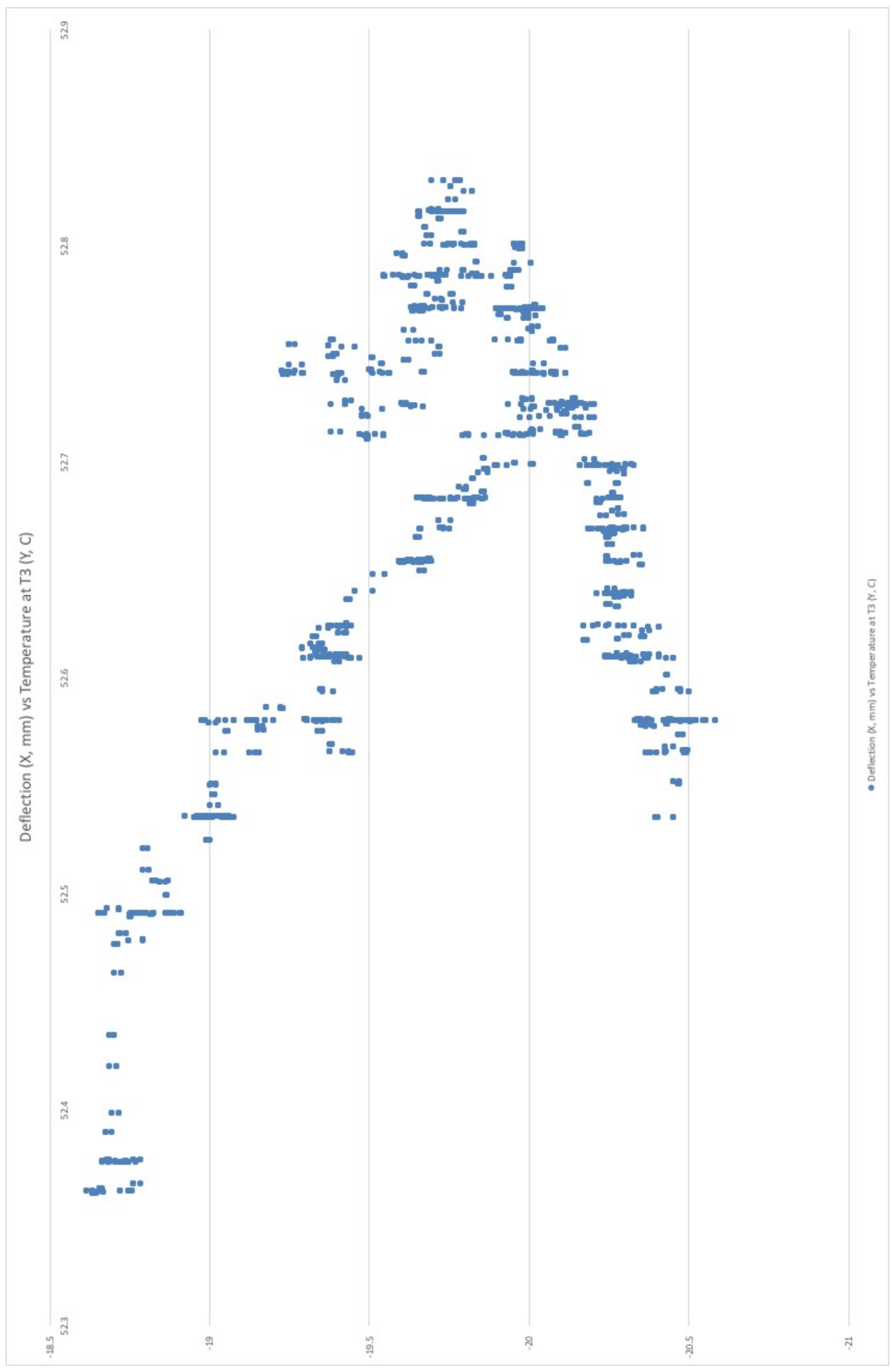

Figure 11c 


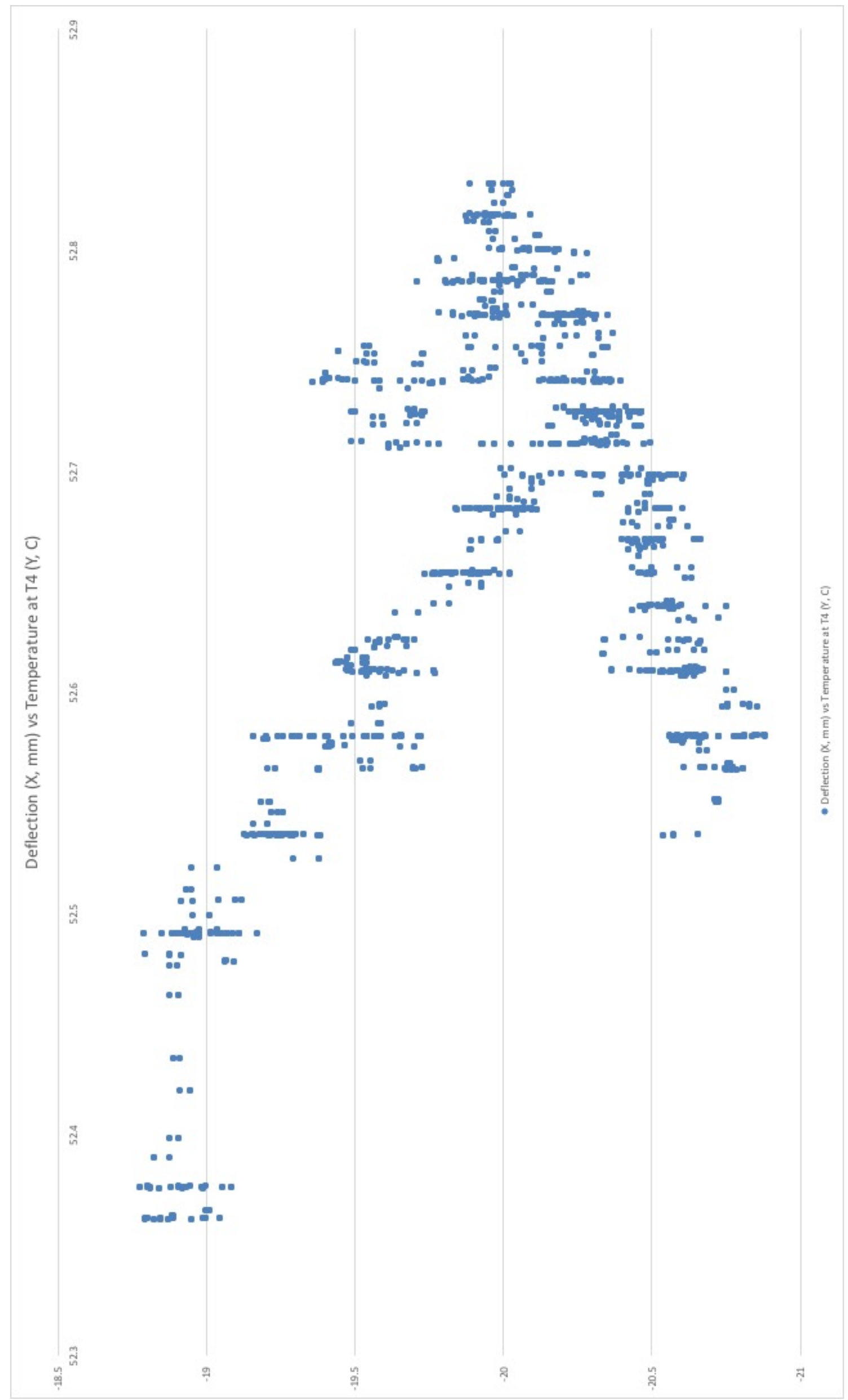

Figure 11d 


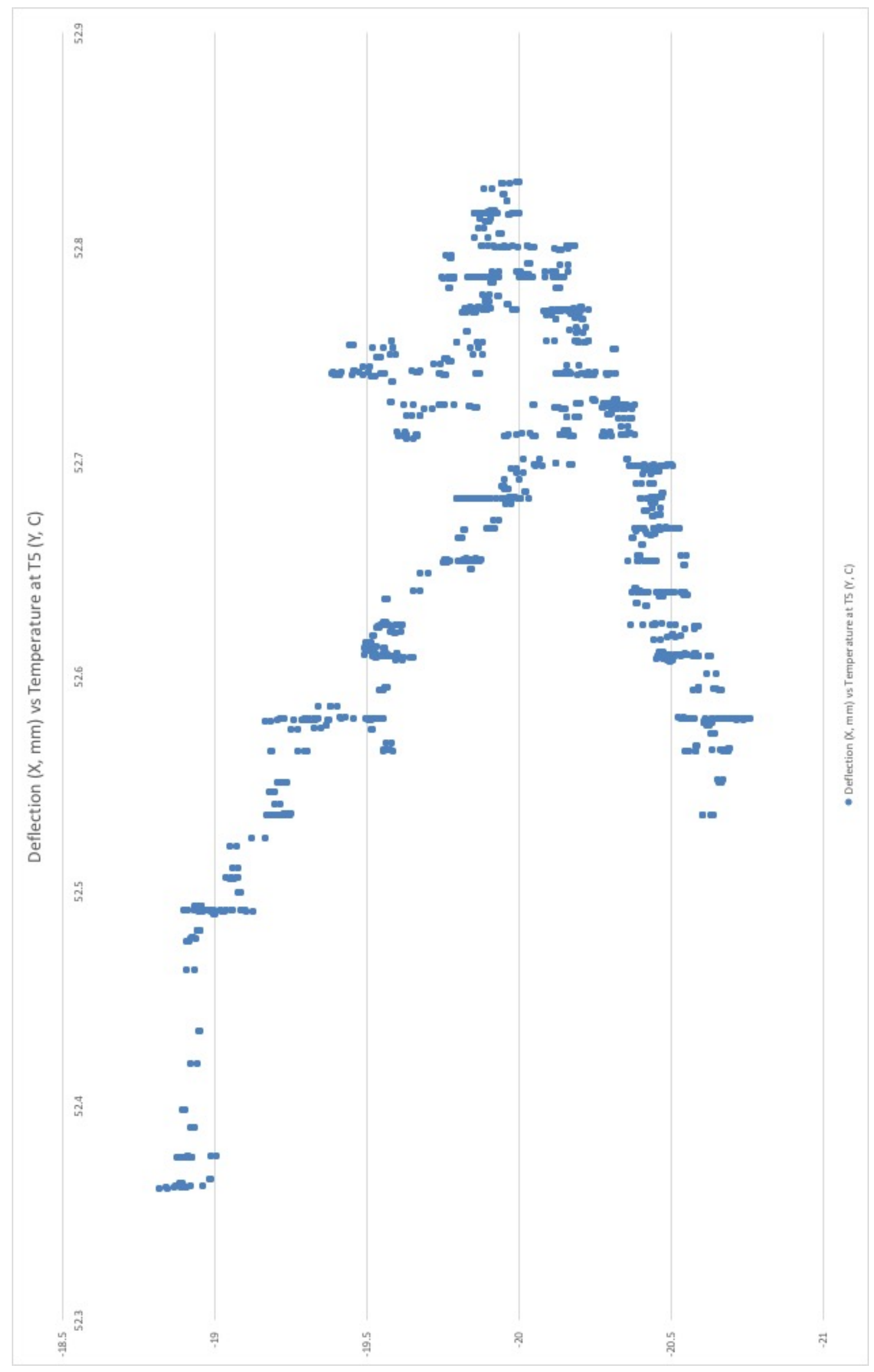

Figure 11e 


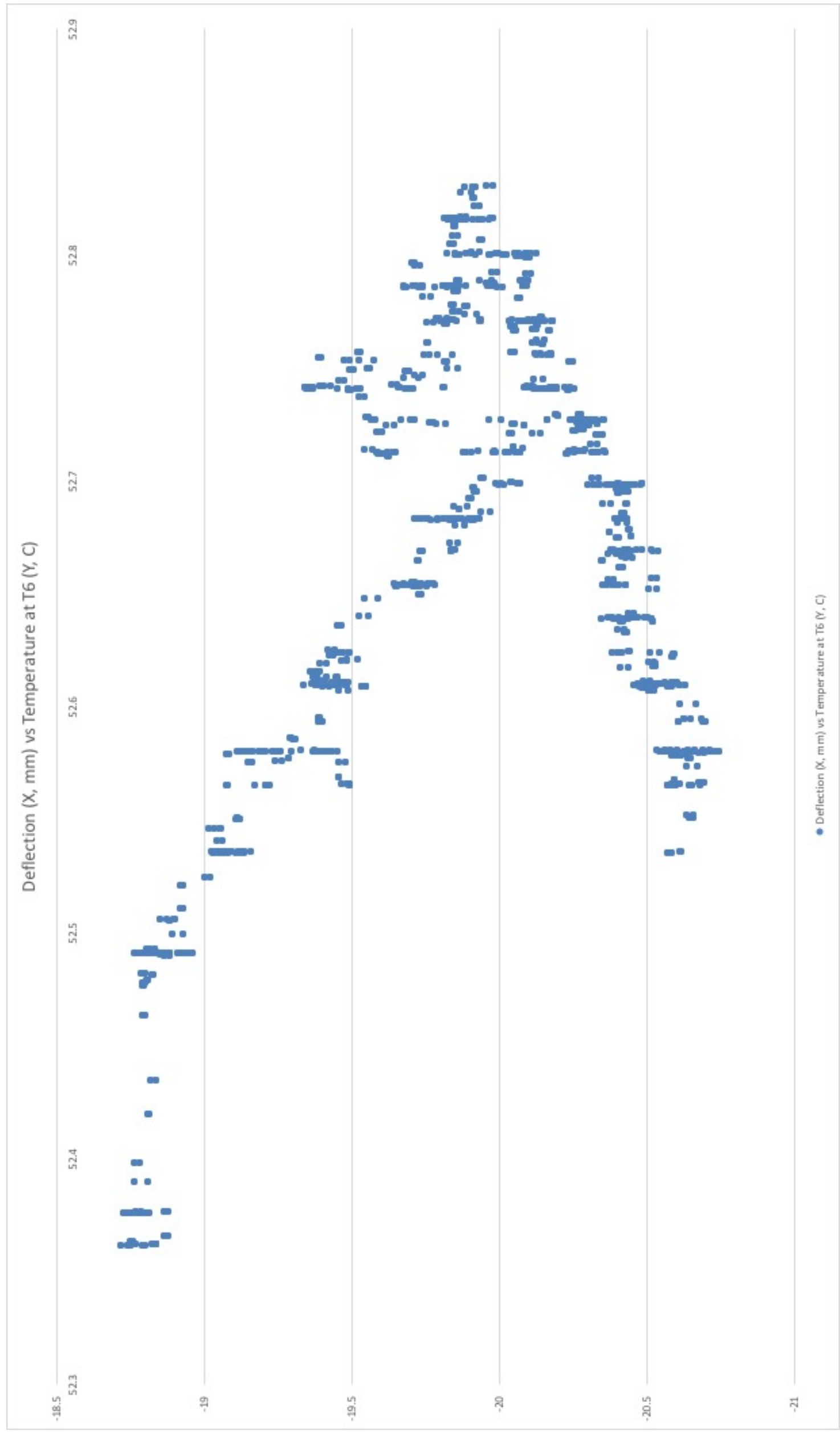

Figure $11 f$ 


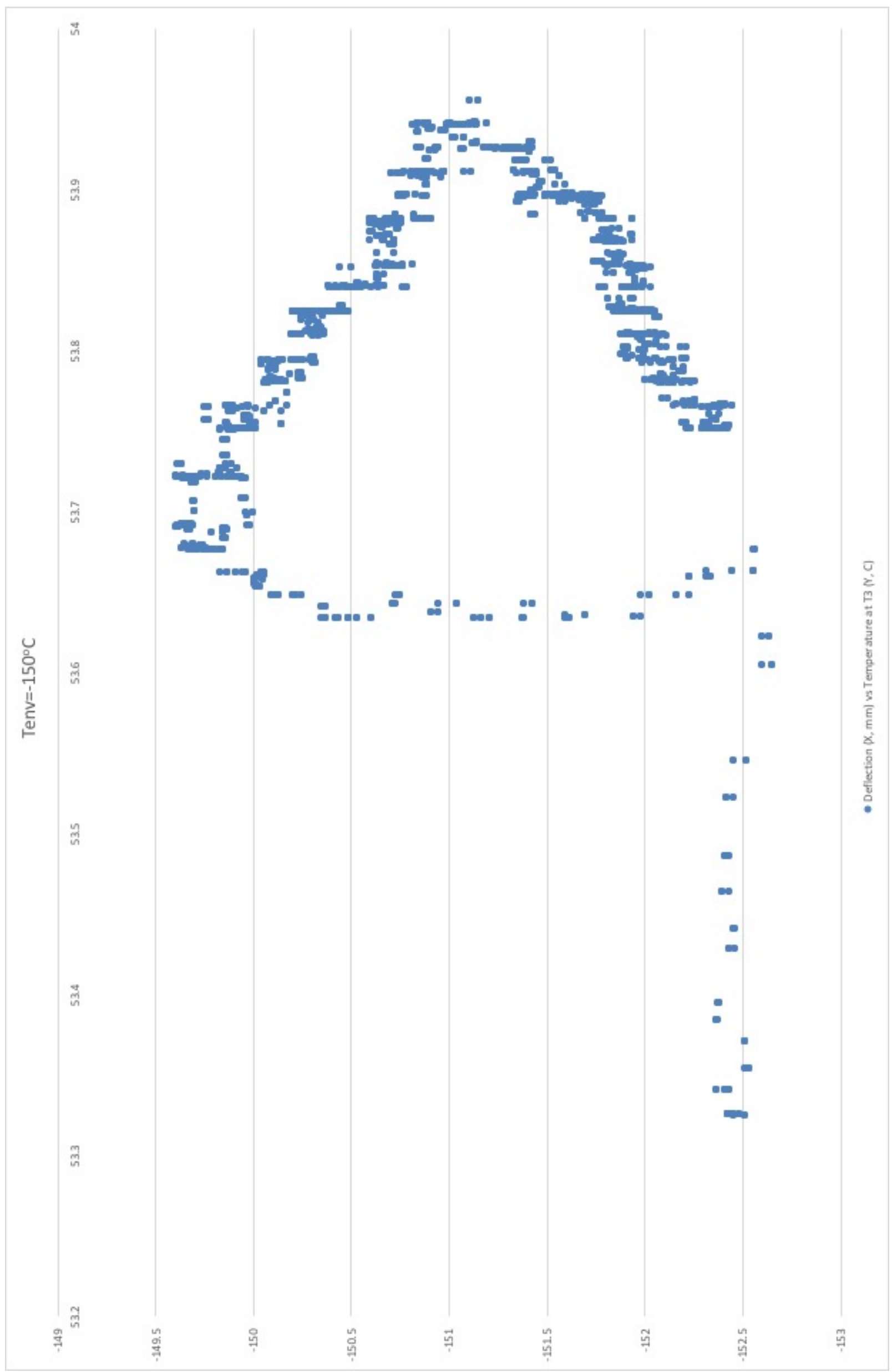

Figure12a 


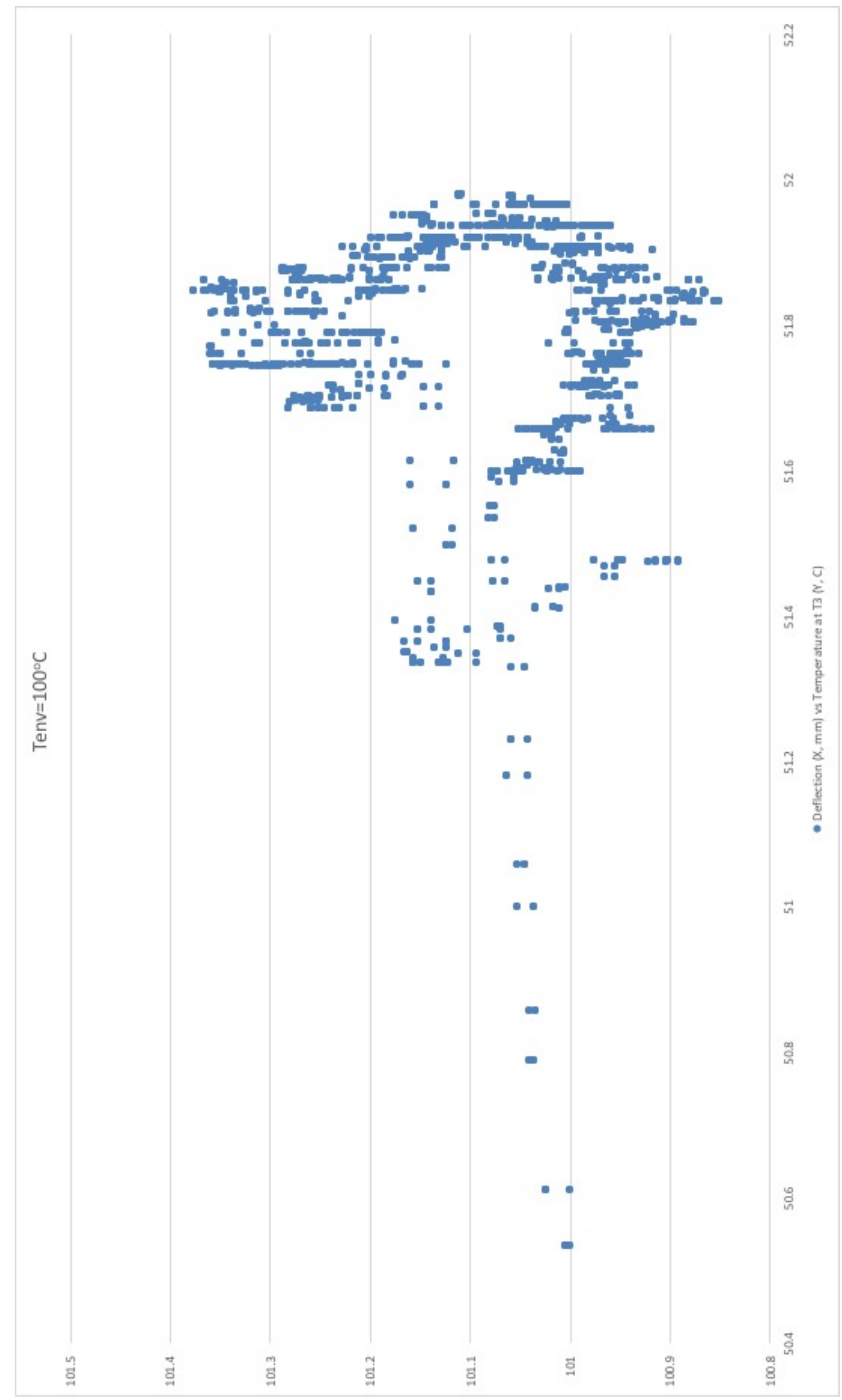

Figure $12 b$ 


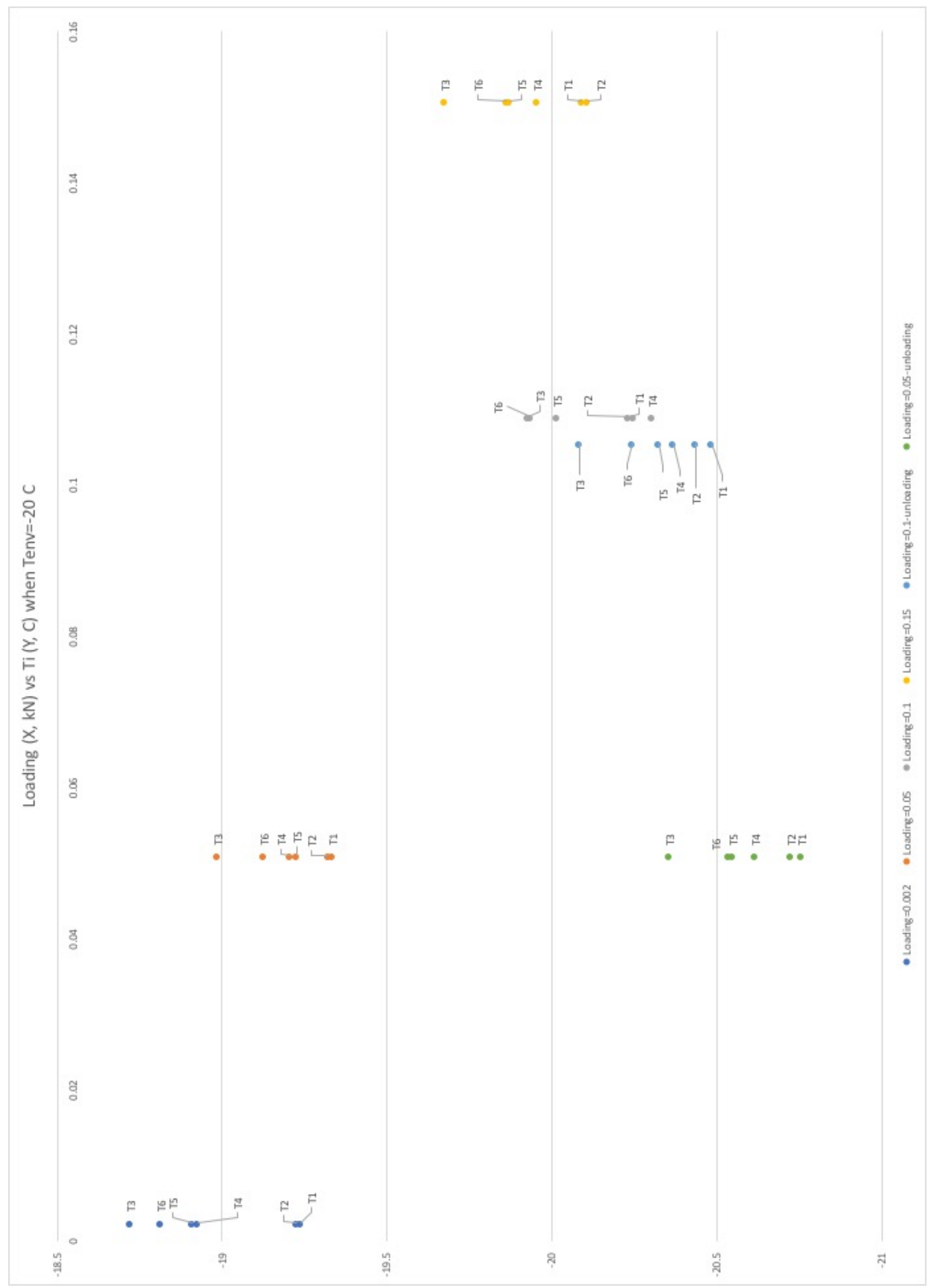

Figure $13 a$ 


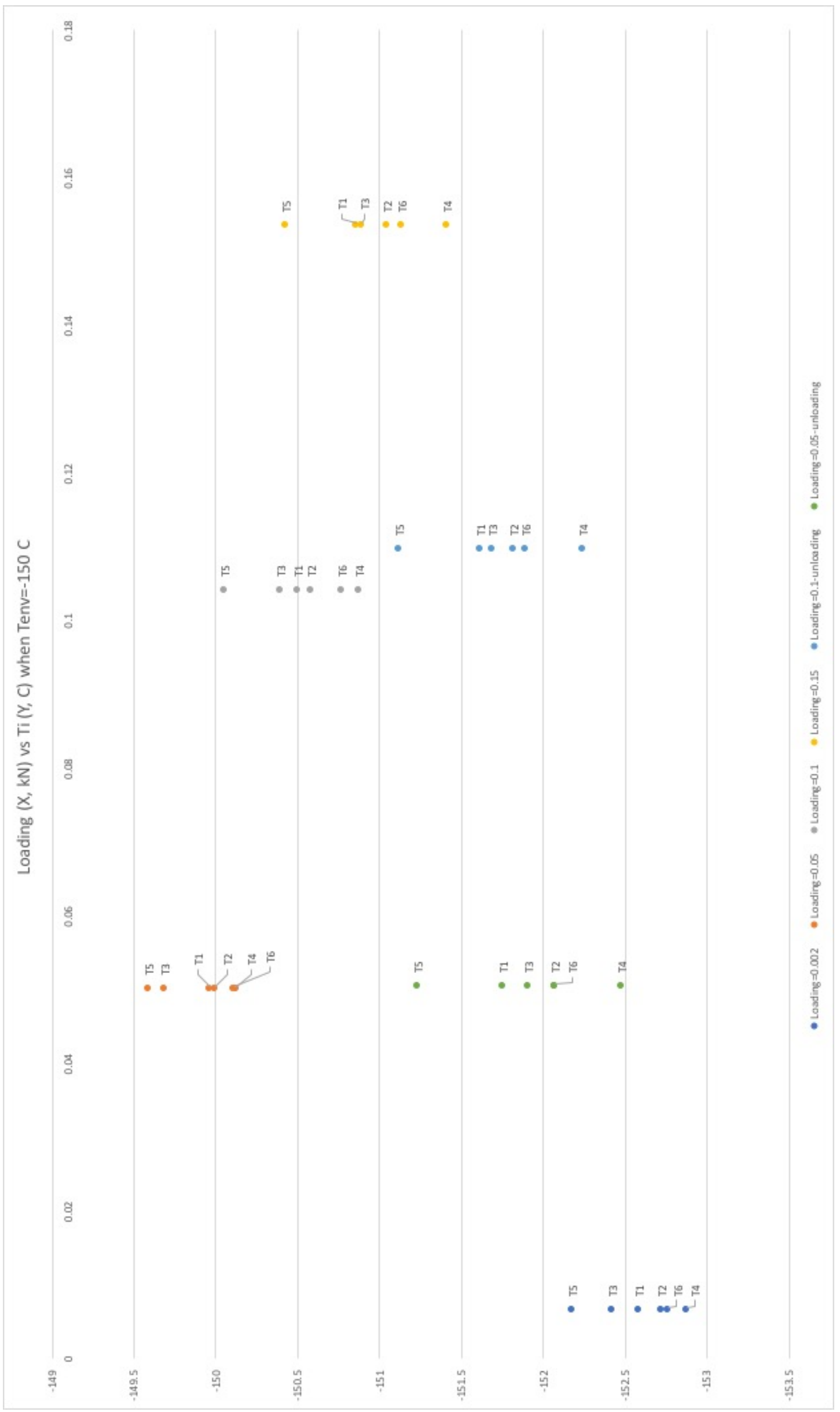

Figure $13 b$ 